\title{
Developmental plasticity in male courtship in Bicyclus anynana butterflies is driven by hormone regulation of the yellow gene
}

Authors: Heidi Connahsa, 1, Eunice Jingmei Tanb, 1 Yi Ting Tera, 1, Emilie Diona, Yuji Matsuokab, Ashley Bearc, and Antónia Monteiroa,b

a Department of Biological Sciences, National University of Singapore, 14 Science Drive 4,

9 Singapore 117543

10 b Yale-NUS College, 16 College Avenue West, Singapore 138527

11 c Department of Ecology and Evolutionary Biology, Yale University

Emails and ORCID numbers:

H. Connahs: hconnahs@gmail.com (ORCID: 0000-0002-6615-5668)

E. J. Tan: eunice.tan@yale-nus.edu.sg (ORCID: 0000-0003-1667-3958)

Y. T. Ter: yitingter@gmail.com

E. Dion: dion.emilie@ymail.com (ORCID: 0000-0001-9296-738X)

A. Bear: abear@nas.edu

Y. Matsuoka: dbsyuji@nus.edu.sg (ORCID: 0000-0002-7610-0708)

A. Monteiro: antonia.monteiro@nus.edu.sg (ORCID: 0000-0001-9696-459X)

Correspondence: Heidi Connahs or Antónia Monteiro, Department of Biological Sciences,

Classification: Biological Sciences, Evolution;

Keywords: transcriptomics, 20-hydroxyecdysone, yellow, transgenic knock-out, courtship plasticity

Running title: Yellow represses male courtship

Authors contributions: YTT, ED, YM, AB, and AM designed the research, EJT performed the transcriptomics, YTT the behavioral work, ED the qPCR work, YM created the transgenic line, AB the injections and brain dissections for transcriptomics work, EJT, YTT, HC, ED, and YM analysed the data; HC wrote a draft manuscript; and HC, EJT, YTT, ED, YM \& AM wrote the final manuscript. 


\section{Abstract}

37 The organizational role for hormones in the regulation of sexual behavior is currently poorly

38 explored. Previous work showed that seasonal variation in levels of the steroid hormone 20-

39 hydroxyecdysone (20E) during pupal development regulates plasticity in male courtship behavior

40 in Bicyclus anynana butterflies. Wet season (WS) males, reared at high temperature, have high

41 levels of 20-hydroxyecdysone (20E) during pupation and become active courters. Dry season

42 (DS) males, reared at low temperatures, have lower levels of 20E and lower courtship rates.

43 Rescue of WS courtship rates can be achieved via injection of 20E into DS male pupae, but it is

44 still unknown whether 20E alters gene expression in the pupal brain, and if so, the identity of

45 those targets. Using transcriptomics, qPCR, and behavioral assays with a transgenic knockout, we

46 show that higher expression levels of the yellow gene in DS male pupal brains, relative to WS

47 brains, represses courtship in DS males. Furthermore, injecting DS males with 20E downregulates

48 yellow to WS levels 4 hours post-injection, revealing a hormone sensitive window that determines

49 courtship behavior. These findings are in striking contrast to Drosophila, where yellow is required

50 for active male courtship behavior. We conclude that 20E plays an organizational role during

51 pupal brain development by regulating the expression of yellow, which is a repressor of the neural

52 circuity for male courtship behavior in B. anynana. This work shows that similar to vertebrates,

53 hormones can also play an organizational role in insect brains, leading to permanent changes in

54 adult sexual behavior. 


\section{Significance Statement}

58 Behavioral plasticity in adult insects is known to be regulated by hormones, which activate

59 neural circuits in response to environmental cues. Here, we show that hormones can also regulate

60 adult behavioral plasticity by altering gene expression during brain development, adjusting the

61 insect's behavior to predictable seasonal environmental variation. We show that seasonal

62 changes in the hormone $20 \mathrm{E}$ alters expression of the yellow gene in the developing pupal brain of

63 Bicyclus anynana butterflies, which leads to differences in male courtship behavior between the

64 dry and wet seasonal forms. This work provides one of the first examples of the organizational

65 role of hormones in altering gene expression and adult sexual behavior in the developing insect

66 brain. 


\section{Introduction}

69 Behavioral plasticity is essential for animals to adapt to environmental variation and it is often

70 triggered by hormonal changes that organize or activate neural circuits in the brain (1-3).

71 Seasonal changes in temperature and photoperiod can serve as important cues that alter hormone

72 levels and sexual behavior in a wide range of vertebrate and invertebrate taxa (4). Precisely how

73 hormone signaling influences sexual behavior in most animals however, is not well known (5).

74 In vertebrates, hormones are considered to play both a brain organizational role, during

75 development, as well as a behavioral activational role in adults, compared to just an adult

76 activational role in insects $(6,7)$. This conceptual framework describes whether hormones

77 permanently organize neural circuitry during early critical periods that later influence adult

78 behavior, or whether they modulate behavior by activating existing neural circuits in response to

79 external cues $(7,8)$.

Sexual behavior in insects has traditionally been viewed as a consequence of cell-autonomous

82 processes taking place during brain development, and involving sex determination genes (6) such

83 as fruitless and doublesex (9). The role of insect hormones is typically described as playing an

84 activational role, allowing rapid and reversible behavioral changes, such as activating neural

85 circuits that regulate pheromone communication or sexual receptivity (10-13). However,

86 hormones have also been proposed to play an organizational role in insects, for instance in the

87 regulation of behavioral polyphenisms in honeybees and locusts (7) and sexual maturity in

88 Drosophila (14). Yet, no evidence is available for the organizational role of steroid hormones in

89 driving sexual behaviors in adult insects, similar to the role of steroid hormones in vertebrate

90 sexual differentiation, where exposure to different hormone levels during ontogeny leads to

91 discrete, fixed differences in neural development and sexual behaviors (7).

93 For insects living in seasonal environments, hormones could play an organizational role earlier in

94 development to ensure that sexual behavior is optimized for particular environmental conditions

95 that will be prevalent upon adult emergence (15). An example of a species where such a brain

96 organizational role may be happening is the African seasonal polyphenic butterfly, Bicyclus

97 anynana. This species shows an interesting sex role reversal between seasonal forms that

98 develop at different temperatures, and where temperature cues in the arrival of different seasons. 
99 In particular, wet season (WS) males, reared at high temperatures, play the active courting role,

100 while DS males, reared at low temperatures, do much less courtship and become, instead, the

101 choosy sex (16). The adaptive reason driving courtship plasticity in males is associated with

102 increased reproductive costs for DS males, which provide females with beneficial

103 spermatophores (16). Provision of this spermatophore ultimately shortens DS male lifespan, but

104 lengthens DS female lifespan and helps them survive through the more stressful and resource-

105 limited dry season $(15,16)$. While the behavioral ecology of these butterflies may explain

106 seasonal variation in male courtship rates, the neural re-wiring that switches the male behavior is

107 completely unknown.

108

109 In B. anynana, signaling of the hormone 20-hydroxyecdysone (20E) during early pupal

110 development has been shown to regulate male courtship (17). In DS males, throughout pupal

111 development, there are significantly lower levels of 20E titers circulating in the hemolymph than

112 in WS males (17). The reduced courtship of DS males, however, can be switched to the WS

113 active courting form by rearing pupae at higher temperatures during the first $50 \%$ of pupal

114 development (15) or, alternatively, by keeping the pupae at low temperatures but injecting them

115 with $20 \mathrm{E}$ at $30 \%$ of pupal development (17). These experiments suggest that this pupal stage is a

116 critical period that determines male sexual behavior and that $20 \mathrm{E}$ may play an organizing role in

117 the developing male brain of B. anynana. However, we currently have no direct evidence that

$11820 \mathrm{E}$ acts specifically on the brain to alter expression of genes that regulate male courtship

119 behavior in adults. High levels of 20E could upregulate genes required for active courtship such

120 as those described for Drosophila including fruitless, doublesex and yellow $(9,18,19)$.

121 Alternatively, 20E signaling may not lead to appreciable differences in the neural circuitry of dry

122 and wet season male brains, but may instead influence other phenotypic traits that are also

123 important in courtship behavior such as pheromone production (20) or the UV brightness of

124 eyespot centers (16).

125 


\section{Results}

Genes involved in melanin synthesis, dopamine metabolism and JH signaling are differentially

\section{expressed in pupal brains}

134 To evaluate the direct organizational effects of $20 \mathrm{E}$ on the pupal brain of B. anynana males, and identify changes in gene expression levels that could impact the future sexual behavior of males, we compared the transcriptome of DS male brains injected with $20 \mathrm{E}$ at $30 \%$ pupal development (referred to as DS20E thereafter) with DS and WS male brains injected with a vehicle solution at the same developmental stage (DSV and WSV, respectively) (Fig. 1). RNA-seq extractions yielded a total of $2.11 \times 108$ raw reads from 12 RNA-seq libraries. All read data was used to produce a transcriptome comprising of 1,403,420 total Trinity transcripts and 689,657 Trinity genes with an N50 length of 973 (full summary statistics are provided in Table S1 and Fig. S1).

142 Mapping of the raw reads back to the transcriptome revealed that the overall alignment rate was

143 98.83-98.98\%. Processing the transcriptome through CD-HIT (21) identified 1,045,896 unigenes

144 in the transcriptome at 0.95 similarity. We identified 399 differentially expressed genes (DEGs)

145 between DSV and WSV pupal brains, 302 were upregulated and 97 were downregulated in DSV.

146 Comparing DS20E pupal brains to WSV, we identified 399 DEGs, 291 were upregulated and

147108 were downregulated in DS20E. Comparing DS20E pupal brains to DSV we identified 151

148 DEGs, 79 were upregulated and 72 were downregulated in DS20E. Overall, the smaller number

149 of differentially expressed genes observed between DSV and DS20E (151) compared to DSV

150 and WSV (399) suggest that the DS20E brain transcriptome profile was more similar to DSV

151 than WSV at 2 hours post-injection (Fig. S2 heat map). The full list of DEGs can be found in

152 Table S2.

154 Genes known to be important in male courtship behavior such as fruitless and doublesex (22) were 155 not differentially expressed at $30 \%$ of pupal brain development. However, the melanin pathway 156 gene yellow was upregulated in both DSV and DS20E when compared to WSV. We also found 157 that dopamine $N$-acetyltransferase (AANAT1/DAT1) was upregulated in DS20E (but not in DSV) 158 when compared to WSV. Other potential genes of interest pertaining to courtship behavior 159 included Juvenile hormone (JH), which was downregulated in DSV compared to WSV, and 160 Juvenile hormone epoxide hydrolase-like (which hydrolyses $\mathrm{JH}$ ) was upregulated in DSV and 161 DS20E when compared to WSV. Genes involved in neural development included neuropeptide 
CCHamide2, Neural Wiskott-Aldrich syndrome protein and lethal 2 essential for life l(2)efl. These genes were downregulated in DSV compared to WSV with l(2)efl also downregulated in DS20E compared to WSV. Fig. 2 summarizes the log-fold change values and $p$-values of the top 10 annotated DEGs. See table S3 for a descriptive list of the DEGs associated with neural

166 development.

\section{E downregulates the expression of yellow 4 h after injections}

169 From the transcriptomics analyses, we did not identify interesting candidate genes with a regulation pattern consistent with the high courtship of WSV and DS20E injected males, and the low courtship of DSV males. We thus decided to explore further the pupal brain expression of yellow because it was previously shown to affect courtship behavior in Drosophila melanogaster $(18,23)$ and was found to be upregulated in both DS treatments compared to WS. We hypothesized that $20 \mathrm{E}$ may affect yellow expression at a later stage post injection, impacting the courtship behavior in adults. To confirm the regulation of yellow expression by $20 \mathrm{E}$ in male pupal brains, we used qPCR to measure the relative expression of yellow in the brains of developing pupae at 3 different time points after injections of the hormone. Similar to the transcriptomics experiment, we injected 20E in DS male pupae at 30\% development, and a vehicle solution in both DS and WS pupae at the same stage, and assessed the relative levels of yellow in dissected pupal brains at 2 , 4 , and 24 hours post injection.

Two hours post-injection, the levels of yellow were about 2.5 times higher in pupal brains of both DSV and DS20E compared to the level of expression in WSV pupal brains, (mirroring our RNA184 seq results), although the expression levels were not significantly different (Fig. S3, ANOVA: F

$185=0.50, \mathrm{p}=0.62)$. However, at 4 hours post-injection, the expression of yellow increased

186 significantly by about 8-fold in DSV compared to WSV pupal brains (Fig 3, ANOVA: F = 5.43, $187 \mathrm{p}=0.023$; post-hoc analysis WSV-DSV: adj. $\mathrm{p}=0.027$ ), while the level of yellow expression in 188 DS20E remained low, similar to those of WSV brains (ANOVA post-hoc analysis WSV-DS20E: 189 adj. $\mathrm{p}=0.79$ ). Twenty-four hours post-injection, expression levels of yellow in the pupal brains 190 of DSV and DS20E were respectively 2.8 and 3.7 times higher than in WSV (Fig. S3). Relative

191 levels of yellow expression were significantly higher in DS20E than in WSV pupal brains

192 (ANOVA: $F=4.12, p=0.046$; post-hoc analysis WSV versus DS20E: adj. $p=0.046$ ). These 
193

results demonstrate that a single injection of $20 \mathrm{E}$ into DS pupae at $30 \%$ of development was sufficient to decrease yellow expression levels in DS20E to WSV levels at 4 hours post-injection. This single injection did not impact yellow levels at the earlier $2 \mathrm{hr}$ time period, nor keep yellow levels low at 24 hours post injection, suggesting that a short interval of time around $30 \%$ pupal development encompasses a hormone-sensitive window in which yellow is downregulated by 20E to WS levels.

\section{Yellow mutant males courted more frequently and for a longer duration than Wt males}

We hypothesized that Yellow may be a repressor of male courtship as DS males exhibit lower courtship than WS males and have significantly higher expression of yellow during pupal brain development. To test this hypothesis, we generated a Yellow mutant homozygous line in $B$. anynana to investigate if loss of Yellow function leads to elevated levels of courtship in DS males alone or in both DS and WS males (Fig. S4). Using this Yellow knockout (KO) line, we compared the duration and frequency of the Yellow mutant and the wildtype (Wt) male courtship sequence, including copulation. Yellow mutant males courted for a longer duration (WS: $\mathrm{t}=2.181, \mathrm{p}=$ 0.0323; DS: $\mathrm{t}=2.083, \mathrm{p}=0.0416$; Fig. 4a) and more frequently (WS: $\mathrm{z}=4.165, \mathrm{p}<0.0001$; DS: $\mathrm{z}=2.629, \mathrm{p}=0.00855$; Fig. $4 \mathrm{~b}$ ) than Wt males regardless of seasonality. In addition, DS Yellow mutant males remained in copulation longer $(t=2.174, p=0.039$; Fig. $4 \mathrm{c})$ than DS Wt males.

Because Yellow males have a lighter overall pigmentation, despite being identical in the brightness of a known sexual ornament, the eyespot's ultraviolet reflecting white center on the ventral and dorsal sides of the forewing (Fig. S5) $(24,25)$, we repeated these male courtship observations using decapitated females. Decapitation prevents important visual cues detected by a female from impacting a male's behavior, such as more intense courtship provoked by a female's increased rejection behavior (26). Yellow mutant males still courted for a longer duration (WS: $\mathrm{t}=2.083, \mathrm{p}$ $=0.0416$; DS: $\mathrm{t}=2.269, \mathrm{p}=0.0266$; Fig. 4a) and more frequently (WS: $\mathrm{z}=10.59, \mathrm{p}<0.0001$; DS: $\mathrm{z}=8.246, \mathrm{p}<0.0001$; Fig. 4b) than Wt males regardless of seasonality (see also Fig. S6). This result indicates that Yellow alters male courtship behavior independently of the female's behavior towards those males. 
224 Yellow mutant males courted more frequently and copulated longer in their DS form than WS form

225 To test whether differences in Yellow expression levels were sufficient to explain courtship

226 differences between the seasonal forms, we compared the amount of courtship between DS and

227 WS Yellow mutant males. If Yellow, alone, was responsible for courtship differences between the

228 forms then DS and WS Yellow mutant males should display similar levels of courtship. DS Yellow

229 mutant males courted live females more frequently $(z=2.324, p=0.0201$; Fig. $4 b)$ and copulated

230 longer $(t=2.174, p=0.039$; Fig. $4 c)$ than WS Yellow mutant males. Similar behavior was

231 observed in males courting decapitated females, with DS Yellow mutant males courting more

232 frequently $(z=2.454, p=0.0141$; Fig. $4 b)$ and copulating longer $(t=-2.34, p=0.032$; Fig. $4 c)$

233 than their WS counterparts. 


\section{Discussion}

237 In insects, hormones are typically assumed to regulate sexual behavior by activating existing

238 neural circuits that control processes such as sexual maturation, memory formation and

239 pheromone communication (11, 27-29). Recently, it has been shown that hormones can also

240 regulate sexual motivation by repressing activation of existing neural circuits (5). It remained

241 unclear, however, whether exposure to different levels of hormones earlier in development could

242 organize neural circuits that affect sexual behavior in adults. Here, we provide evidence that the

243 ecdysteroid 20E plays an organizational role during pupal brain development in B. anynana by

244 repressing expression of the yellow gene which leads to seasonal differences in male courtship

245 behavior.

Yellow is regulated by $20 E$ during pupal brain development and functions a repressor of male

248 courtship in B. anynana

249 We show that yellow is significantly upregulated in the pupal brains of DS male butterflies which

250 court less than WS males. This increase in yellow expression appears to be in response to

251 seasonal fluctuations in 20E, as injection of this hormone into DS males at 30\% of pupal

252 development was sufficient to suppress yellow expression to levels observed in WS pupal brains

253 at 4 hours post-injection, as well as to rescue WS courtship levels in adults (17). These results

254 suggest that this period encompasses a critical window during brain development which is

255 sensitive to circulating levels of 20E. High levels of yellow in DS males suggested that yellow

256 was a repressor of courtship. This was confirmed by knocking out yellow in B. anynana and

257 observing male Yellow mutants exhibiting increased courtship frequency and duration compared

258 to wildtype males of both seasonal forms. Given that Yellow WS mutants displayed more active

259 courtship than wildtype WS males, this suggests that low levels of yellow expression are still

260 required in wildtype WS males to reduce courtship and optimize energy expenditure, as

261 increased wing fluttering observed in the Yellow KO line did not translate to increased mating

262 success.

264 Comparing the behavior of Yellow mutant males between seasonal forms produced additional

265 insights into the role of yellow in regulating male courtship plasticity. The complete loss of yellow

266 led to DS males courting more than WS males. This result was surprising as it suggests that 
267 removal of Yellow inverts the relative amount of courtship performed by WS and DS males; It 268 leads DS males to court more than WS males. This suggests that Yellow is required for inverting 269 a biased level of courtship that would take place in these butterflies driven by temperature alone.

270 Without the action of yellow, males reared at high temperature during development would court 271 less than males reared at low temperatures. This indicates that the high levels of yellow expression

272 in the brains of DS males is absolutely essential to produce the low levels of courtship in this 273 seasonal form, and that other factors controlled by rearing temperature and by $20 \mathrm{E}$ are biasing 274 adult courtship levels in the opposite direction to those observed in wildtype individuals. These 275 factors can be explored in future.

277 Our findings are in striking contrast to those observed in Drosophila where yellow is required for 278 normal male courtship behavior. Exactly how yellow expression influences male courtship 279 behavior in Drosophila has been a topic of investigation that has yielded conflicting results. An 280 early study suggested that yellow mutant males were less successful during courtship and 281 displayed reduced wing vibrations (30). Further tests of these observations showed that 282 mutations in yellow disrupted wing extension during the courtship ritual, preventing males from 283 performing a courtship song which is required for male mating success $(18,31)$. However, recent 284 work by Massey et al. argued that a lack of melanization in the sex combs of yellow mutants, 285 rather than any impairment in neural circuitry affecting courtship song, was the trait that 286 prevented males from successfully grasping females (19), an idea that was proposed earlier (32). 287 It is possible that the fly laboratory stock might have evolved between the earlier and the later 288 experiments, as the courtship observations repeated by Massey et al., produced different results 289 from the original observations on the same stock (30). All research to date on yellow mutants in 290 Drosophila, however, clearly demonstrate that yellow is absolutely required for successful male 291 courtship.

293 yellow may influence courtship behavior in B. anynana via the dopaminergic signaling pathway

294 Dopamine is an important catecholamine neurotransmitter which regulates a variety of behaviors 295 including motor output, drive, arousal, pleasure and memory $(33,34)$. Dopaminergic signaling 296 has been shown to regulate not only mating drive but also persistence and duration of mating in 297 male Drosophila $(35,36)$. Melanin synthesis enzymes are expressed in the Drosophila brain and 
may be involved in the production of neuromelanin in dopaminergic neurons (37). Yellow is thought to function as a dopachrome conversion enzyme (DCE) in the melanin pathway converting L-Dopa to Dopa-melanin $(38,39)$. L-Dopa is also used as substrate for dopamine which is involved in both cuticle pigmentation and neurotransmission (36). Thus, variation in yellow expression could alter the availability of L-Dopa for dopamine synthesis, with higher expression of yellow in DS brains leading to reduced L-Dopa. Alternatively, Yellow may physically bind to dopamine, as demonstrated in a study of salivary proteins in sandflies (40). Thus, the increased expression of yellow in DS brains could lead to a reduction in dopamine availability, which may inhibit courtship behavior. In Fig. 5, we suggest a possible mechanism of Yellow involvement in the pathway converting tyrosine to L-Dopa in dopaminergic neurons.

Currently we have no direct evidence that dopamine levels differ between DS and WS Bicyclus brains. However, the expression profile of a few genes in our transcriptome analyses may provide some indirect evidence. We found that dopamine $\mathrm{N}$-acetyltransferase, AANAT/DAT1 was upregulated in pupal brains of DS20E (but not in DSV) as compared to WSV brains. This

313 may indicate a transient response to the $20 \mathrm{E}$ injection. The function of AANAT is to metabolize

314 and inactivate secreted dopamine in the synapse shortly after release $(33,37)$. In young female

315 Drosophila virilis, higher titers of $20 \mathrm{E}$ leads to an increase in dopamine, although this appears to

316 be associated with reduced activity of AANAT (41). However, in retinal cells of fish, AANAT

317 activity is positively correlated with dopamine levels (42). An increase in dopamine induced by

318 20E would provide a mechanistic explanation as to why DS male pupa injected with 20E display

319 active WS courtship behavior. Functional experiments measuring or manipulating dopamine

320 levels, however, are required to test the hypothesis that dopamine levels are higher in WS male

321 pupal brains.

323 We also observed changes in Juvenile hormone $(\mathrm{JH})$ signaling, which is known to interact with

324 dopamine to affect sexual maturity and courtship behavior in Drosophila, likely through changes

325 in neural development $(14,43)$. In DS pupal brains, JH was downregulated and Juvenile

326 hormone epoxide hydrolase (JHE), which degrades JH (44), was upregulated. These findings

327 could indicate that dopamine levels are low in DS male pupal brains as dopamine increases $\mathrm{JH}$

328 titers in young female D. virilis by inhibiting its degradation (45). $\mathrm{JH}$ is also associated with 
increased dopamine levels in male honeybees (46). Although we also see an upregulation of JHE

330 but no longer a downregulation of JH in DS20E, this may reflect a response to changing levels of

331 dopamine. Interactions between 20E, JH, dopamine and AANAT in Drosophila represent a

332 complex pathway as depicted in $(41,47)$ thus, we must interpret our findings with caution.

333 However, given that this is an important pathway for regulating courtship behavior in

334 Drosophila, the differential expression of these genes in our transcriptome analyses suggest their

335 possible involvement in regulating courtship behavior in B. anynana.

Drosophila courtship genes do not impact Bicyclus courtship behavior at this pupal stage

338 A number of genes that are known to be important for male courtship in Drosophila (fruitless,

$339 d s x$ crol, lola, cadN and chinmo) (22), were surprisingly not differentially expressed between any

340 of our treatment groups and all showed very low levels of expression (Fig. 2). Thus, it appears

341 that in B. anynana these genes do not influence neural re-wiring occurring at this particular stage

342 of brain development. However, we cannot exclude the possibility that these genes are

343 upregulated at a later time point after the 20E injection. We did, however, identify some other

344 differentially expressed genes including Neural Wiskott-Aldrich syndrome protein (N-WASP),

345 CCHamide2 and lethal 2 essential for life (l(2)efl) that may be important in neural development

346 and behavior and could serve as interesting candidates for future studies (see Table S3).

\section{Conclusions}

349 Here, we show that male DS butterflies court less than WS butterflies due to temperature-induced

350 changes in levels of $20 \mathrm{E}$, which alter the expression of the yellow gene during pupal brain development

351 leading to differences in adult courtship behavior. In B. anynana, yellow functions as a repressor of male

352 courtship and is a downstream target of 20E. Our results suggest potential interactions of $20 \mathrm{E}$ on JH and

353 dopamine signaling, a circuit that is well described in Drosophila. Future studies examining dopamine

354 levels between the seasonal forms and the individual role of $20 \mathrm{E}$ and $\mathrm{JH}$ on dopaminergic signaling

355 would help clarify mechanistically why the yellow gene functions as a repressor of male courtship in

356 these butterflies. We propose an organizational role for 20E, suggesting convergence in hormone

357 regulation of sexual behavior in insects and vertebrates. For animals living in seasonal environments,

358 selection may favor adaptations that use external cues to optimize behavior, such as employing 
359 environmentally induced hormones like 20E to organize neural circuits during critical windows of brain

360 development.

361

\section{Acknowledgements}

363 We would like to acknowledge Dong Qiang Cheng, for helping EJT with the hardware issues on

364 lab server; Jan Gruber, for advising EJT with the Linux operating system and also Firefly Farms

365 in Singapore for supplying corn for larval rearing.

366

\section{Funding}

368 EJT was supported by a Postdoctoral Fellowship from Yale-NUS College. We thank NSF award

369 DDIG IOS-1110523 to AM and AB, Ministry of Education Singapore, award MOE2018-T2-1-

370092 to AM, and National Research Foundation, Singapore, Investigatorship award NRF-

371 NRFI05-2019-0006 to AM.

372

373

374 


\section{Methods}

\section{Transcriptome assembly and analyses}

\section{Sample collection and Illumina $(R) R N A$-seq experiments}

To mimic dry and wet season conditions, caterpillars of $B$. anynana were reared under WS and DS temperatures in climate-controlled rooms at $27^{\circ} \mathrm{C}$ and $17^{\circ} \mathrm{C}$, respectively, at $80 \%$ humidity, and a 12:12 hr light:dark photoperiod. Caterpillars were fed corn plants ad libitum until pupation._Pupae were staged, such that the percent of pupal development was known for all individuals. At 30\% of pupal development (day 2 in the WS butterflies and day 6 in the DS butterflies) DS pupae were injected with either $3 \mu \mathrm{l}$ of $2000 \mathrm{pg} / \mu \mathrm{l}(6000 \mathrm{pg}$ total) $(10 \% 20 \mathrm{E}$ in $\mathrm{EtOH}+90 \%$ saline $)$ of $20 \mathrm{E}$ (Sigma-Aldrich $\left.{ }^{\circledR}\right)$ or with $3 \mu$ l of vehicle (10\% EtOH and $90 \%$ saline) and WS pupae were injected with $3 \mu \mathrm{l}$ of vehicle in the lateral posterior region of the fifth abdominal segment. The injections were done at $1200 \mathrm{~h}$ and the brains were dissected two hours later, at $1400 \mathrm{~h}$. We chose to inject the animals two hours before collection in order to give the $20 \mathrm{E}$ time to circulate through the open circulatory system of the insect to reach the brain and to affect gene expression in this tissue. We

392 chose this time point after injection to collect the samples because previous studies have 393 demonstrated that genes, which respond early to 20E signaling are expressed about 2 hours after exposure to $20 \mathrm{E}(48,49)$.

Samples from each treatment were collected on each collection day in order to reduce the confounding effects of day of collection on gene expression. Each sample consisted of three biological replicates of wet season pupal brains following treatment with vehicle only; four biological replicates of dry season pupae treated with vehicle only; and five biological replicates

401 from the brains of five different individual male pupae. Brains were pooled to account for the 402 genetic variation in the colony. The pupal brains were dissected in a solution of ice cold $1 \mathrm{X}$ PBS. 403 After each dissection, the brain was immediately immersed in a 1.5 eppendorf tube containing 500 $404 \mu$ l of TRIzol ${ }^{\circledR}$ reagent (Life Technologies ${ }^{\circledR}$ ) and 3 RNase-free beads (\#SSB14B 1.4mm Stainless 
407 Once all five brains from a particular treatment group were placed in the TRIzol reagent, the brains 408 were immediately homogenized using a Bullet Blender (NEXT>>>ADVANCE®) for three 409 minutes and total RNA was extracted using the trizol-chloroform protocol. DNA was removed 410 using gDNA Eliminator Mini Spin Columns from the RNeasy Plus Micro Kit (Qiagen ${ }^{\circledR}$ ) and

411 following the kit instructions. The quality of the extracted RNA was checked using a ND1000 412 spectrophotometer (NanoDrop ${ }^{\circledR}$ Technologies) and stored at $-80^{\circ} \mathrm{C}$. The samples were submitted 413 to the W.M. Keck Biotechnology Resource Laboratory for Illumina ${ }^{\circledR}$ RNA-Seq. The RNA 414 samples consisted of $4 \mu \mathrm{g}$ of total RNA in $20 \mathrm{ml}$ of water, and was run on a separate lane of a flow 415 cell on a HiSeq2000. The Keck Biotechnology Resource processed the samples following standard 416 Illumina ${ }^{\circledR}$ RNA-Seq protocol.

\section{Transcriptome assembly}

419 We assembled the transcriptome from a total of 12 RNA-Seq libraries. Raw reads of the RNA-seq 420 libraries were uploaded to the SRA database with the SRA accession number PRJNA544388.

421 Prior to performing the transcriptome assembly, we performed quality trimming of the input raw 422 reads using Trimmomatic using the default options (50). We assembled a de novo transcriptome 423 using Trinity 2.4.0 (51) and Bowtie2, following the protocol by Haas et al. (52). The transcriptome 424 was then uploaded to the Transcriptome Shotgun Assembly (TSA) Database, following the TSA 425 guidelines. During this process, transcripts were screened for vector contaminations and any vector 426 and linker sequences were removed. In addition, transcripts smaller than $200 \mathrm{bp}$ were screened 427 and removed from the assembly. This Transcriptome Shotgun Assembly project has been 428 deposited at DDBJ/EMBL/GenBank under the accession GHRJ00000000. The version described 429 in this paper is the first version, GHRJ01000000.

431 To characterize the quality of our transcriptome assembly, we used scripts in the Trinity toolkit. 432 First, we computed assembly statistics, which is the contig N50 value based on the set of transcripts 433 representing $90 \%$ of the expression data, using the TrinityStats.pl script. These assembly statistics 434 for B. anynana brain transcriptome are reported in Table S1. Next, we computed the N50 statistics 435 of the top most highly expressed transcripts that represent $\mathrm{x} \%$ of the total normalized expression 436 data, using the contig_ExN50_statistic.pl script. The N50 statistics are presented in Figure S1. To 437 assess the proportion of raw reads mapped to the transcriptome assembly, we used Bowtie2. We 
438 then extracted transcripts that are most differentially expressed and clustered these transcripts according to their patterns of differential expression using the analyze_diff_expr.pl script from the

440 Trinity toolkit. The clustering analysis indicated that the biological replicates from the same 441 treatment clustered together, as shown in Figure S2.

443 Next, we obtained unigenes for the transcriptome using CD-Hit version 4.6 (21) with similarity 444 set to 0.95 . CD-Hit clustered all sequences with similarity $\geq 95 \%$, retaining only the longest 445 transcript, thus splice variants/isoforms were removed and redundancy was reduced. The 446 transcriptome assembly with unigenes was then used for differential gene expression, described in 447 the next section.

\section{Differential gene expression}

450 To estimate transcript abundance, we used RSEM 1.3.2 (53), a software which uses Bowtie2 (54) 451 to align the transcripts to the transcriptome assembly, thus quantifying gene and isoform 452 abundances. The RSEM output reported normalized expression metrics as fragments per kilobase 453 transcript length per million fragments mapped (FPKM) and transcripts per million transcripts 454 (TPM). Next, we used edgeR 3.28.1 (55), to examine differential expression of genes across the 455 three treatments (DSV vs WSV, DS20E vs DSV and DS20E vs WSV). EdgeR normalizes RNA 456 composition by finding a set of scaling factors for the library sizes that minimize the log-fold 457 change ratios $(\log F C)$ between the samples for most genes. We used the default method in edgeR 458 for computing these scale factors, which is a trimmed mean of Mvalues (TMM) between each pair 459 of samples. Genes with a False Discovery Rate (FDR) of $<0.05$ and $\operatorname{logFC}$ of $\geq 2$ were defined as 460 differentially expressed genes (DEGs).

462 In order to understand the DEGs induced by the hormone treatment, we further annotated the DEGs 463 with Blast2GO 5.2.5. We used the public NCBI Blast service (QBlast) to blast our sequences 464 against the non-redundant protein database using the blastx-fast program. Matched transcripts 465 were filtered using a cut-off E-value of $1 \times 10-3$; otherwise the default settings for Blast2GO were 466 used at each step. To annotate the remaining transcriptome, we performed a local blastx of the 467 assembled contigs against the Bicyclus anynana v1.2 draft genome (56). The annotated 468 transcriptome has been deposited on Dryad and will be made available for publication. 


\section{qPCR sample collection and experiments}

470 Sample collection was similar to the one described above for the RNA seq experiment. We 471 measured the total development time of Wt pupae, and at 30\% development (2.5 and 6.5 days for

472 WS and DS pupae respectively in these rearing conditions), we injected pupae with 20E or vehicle

473 solutions using the same protocol as described above. Pupal brains were dissected 2 hours, 4 hours 474 and 24 hours after injections in ice cold 1X PBS, placed immediately into RNALater (Qiagen, $475 \mathrm{GmbH}$, Hilden, Germany) and stored at $-20^{\circ} \mathrm{C}$ until RNA extraction. We used 5 biological 476 replicates per treatment, each made of 5 pooled brains (for the 2 hours dissections) or 2 pooled 477 brains (for the 4- and 24-hour dissections).

479 Total RNA extraction, including the elimination of genomic DNA, was done using the Qiagen 480 RNeasy Plus Mini Kit (Hilden, Germany) following the manufacturer's instructions. 481 Complementary DNA was synthesized using the RevertAid RT Reverse Transcription Kit 482 (Themoscientific). $10 \mathrm{ng}$ of cDNA were used for qPCR with the KAPA SYBR FAST qPCR Kit 483 (KK4604, KAPA Biosystems, Wilmington, MA, USA) and the experiment run on the Biorad 484 CFX96 system using the TqPCR protocol described in Zhang et al. (57). Primer efficiencies were 485 calculated using $0.5,5$ and $50 \mathrm{ng}$ of cDNA from Wt tissue (with 3 technical replicates). The primers 486 are described in Table S4.

488 We calculated the relative transcript levels using the common based method (58). The Ct values 489 were normalized to the reference gene EFI $\alpha$ and to the average Ct of the WS reference samples. $490 \Delta \mathrm{Ct}$ values from each treatment were compared using a one-way analysis of variance (ANOVA) 491 followed by a post-hoc analysis providing $\mathrm{p}$ values adjusted with the Tukey method. Statistical 492 analyses were performed in R v.4.0.0 (59) implemented in RStudio v.1.2.5042 (60), using Rmisc, 493 car and emmeans packages (61-63).

\section{Generation of CRISPR-attP Yellow knock out line}

496 To establish a Yellow mutant line we inserted an attP sequence into exon 4 of the yellow gene to 497 disrupt its overall sequence (Fig S7). We used a knock-in method through homology directed 498 repair (HDR) using a single-stranded DNA (ssDNA) as a template. The ssDNA construct was 499 made following methods described in (64). The ssDNA contains $66 \mathrm{bp}$ and $60 \mathrm{bp}$ of homologous 
500 sequence around the target region on each side of the attP sequence motif. We injected $500 \mathrm{ng} / \mu \mathrm{l}$ 501 of a sgRNA targeting the yellow gene, $500 \mathrm{ng} / \mu \mathrm{l} \mathrm{Cas} 9 \mathrm{mRNA}$, and $160 \mathrm{ng} / \mu \mathrm{ls}$ DNA into fertilized

502 2-3 hr old embryos. Out of 254 injected embryos, 87 larvae hatched, resulting in 14 adults (6 males 503 and 8 females). We then crossed 3 Go mosaic butterflies (showing some yellow patches of 504 coloration on the wings) with $3 \mathrm{Wt}$ to obtain the $\mathrm{G}_{1}$ generation. To identify which cage contained 505 transgenic butterflies with the attP insertion, we pooled 30 embryos from each cage, extracted 506 genomic DNA, and performed PCR. One out of 3 cages showed a positive band. In cages that were 507 identified as contained transgenic individuals we performed further genotyping of individual 508 larvae using haemolymph PCR (Fig. S7). We isolated 5 transgenics out of 102 G1 genotyped 509 animals. We confirmed that the PCR amplicon flanking the gRNA target site was the expected 510 sequence although it contained 2 substitutions outside the attP sequence (Fig. S7). We crossed 511 these 5 positive $\mathrm{G}_{1}$ butterflies with a Yellow phenotype with Wt counterparts, and then identified

512 heterozygous $\mathrm{G}_{2}$ mutant offspring by haemolymph PCR since B. anynana yellow gene is likely a 513 dominant gene regarding its effect on body color. We further crossed heterozygous G2 butterflies 514 with each other, and obtained a homozygous $\mathrm{G}_{3}$ generation using, again, genotyping via 515 haemolymph PCR.

517 Behavioral Assays

518 Animal husbandry

519 Larvae from both the Yellow CRISPR-attP line and Wt were fed with young maize plants (Zea 520 mays) and adults with mashed bananas ad libitum. Larvae of both lines were reared in WS and DS 521 conditions as described above. Prior to eclosion (Day 0), pupae were separated according to their 522 sex to ensure virginity. Adults that emerged on the same day were then transferred to other cages 523 and dated accordingly.

\section{Behavioral experiments}

526 Behavioral assays were conducted in cylindrical hanging cages $(30 \mathrm{~cm} \times 40 \mathrm{~cm})$ under one full 527 spectrum light tube (Plantmax) and one UV light bulb (Arcadia Marine Blue), at $23^{\circ} \mathrm{C}$, from 17:00 528 to 18:00. This specific time of observation was chosen because B. anynana exhibits crepuscular 529 courtship (17). Visual barriers were placed between cages to prevent mate-copying (65). Within 530 each sex, butterflies used for each assay were of the same age. All butterflies used in the assays 
531 ranged from four to eight days old. Two experiments were performed, one with live females and

532 the other with decapitated females. The treatments were i) two Wt males $\mathrm{x}$ two Wt females, and

533 ii) two Yellow mutant males $\mathrm{x}$ two Wt females (Fig. S4). One of the two males/ females in an

534 assay was dotted with a black marker at both of its ventral hindwings to allow for sex-specific

535 scoring of behavior. The multiple elements of courtship, as documented in Nieberding et al. (66),

536 were scored in the assays: 1) localization (flying to other butterfly), 2) rapid flickering of wings,

537 3) thrusting (touching female's wings with head), and 4) attempting (curling of the abdomen) (Fig.

538 S4). Orientation (orienting body to female's posterior) was not recorded since it was difficult to score or interpret their intent (courtship or coincidence) with that behavior. Latency to mate (time taken from the start of assay to the first mating) and mating duration were recorded as well.

541 Behavioral assays lasted one hour, and quantification of an individual male behavior stopped once 542 the first mating had occurred (i.e. even if one has mated, the other male's behavior is still quantified 543 until its own mating or one hour has lapsed).

545 For decapitation experiments, only females were decapitated to characterize male sexual behavior 546 in the absence of female response (26). The same behavioral scoring as described above was used 547 for this experiment. Decapitated females were first anesthetized in a $-20^{\circ} \mathrm{C}$ freezer for 20 minutes 548 and their heads were removed. Females were pinned through their thorax into opposite sides of the 549 cage as illustrated in Fig. S4c and d. Based on personal observations, males tend to begin courtship 550 when females start moving or signal readiness. Without movement, which was observed in some 551 of the decapitation assays, males do not attempt to court at all, regardless of treatment type.

552 Therefore, to overcome this potential issue, the pins (and therefore the thorax) of decapitated 553 females were moved gently to emulate movement after 30 minutes had passed since the start of 554 the assay. This specific timepoint was used as the average mating latency for live experiments was 555 approximately 30 minutes. Thus, this reduces bias as much as possible, while still managing to test 556 the effect of the yellow gene in male courtship behavior.

Statistical analysis

559 The data was evaluated for equality of variances and normality using the Levene's test and 560 Shapiro-Wilk test, respectively. Total duration and frequency of courtship were calculated by 561 adding up the duration/ frequency of all the courtship elements displayed (localising + flicker + 
562 thrust + attempt) during the observation period. A Generalised Linear Model (GLM) with a 563 Tweedie distribution (Gamma family; tweedie package (67)) was done to test the impact of the 564 treatment type (Yellow/ WT) and season (WS/ DS) on the total duration of courtship. A Tweedie 565 distribution (Gamma) was used due to the high number of zeroes and the skewness of data. The 566 impact of the treatment type (Yellow/ WT) and season (WS/ DS) on the frequency of each 567 courtship element was compared using a Zero- Inflated Poisson Model (pscl package (68)). Both 568 mating latency and mating duration of the mated pairs were compared using independent $\mathrm{t}$ - tests. 569 Chi-square tests were carried out to identify any associations between treatment type and mating 570 success. Statistical tests and figures were done with IBM SPSS Statistics 25 and R-4.0.2 (59). The 571 spectral data of eyespots was visualized using the pavo package (Fig. S5 (69)). Spectral analysis 572 was done through calculating area under curve (AUC) for each eyespot replicate and the AUC 573 analyzed using an ANOVA with post-hoc Tukey test in R. 


\section{Figures}

576

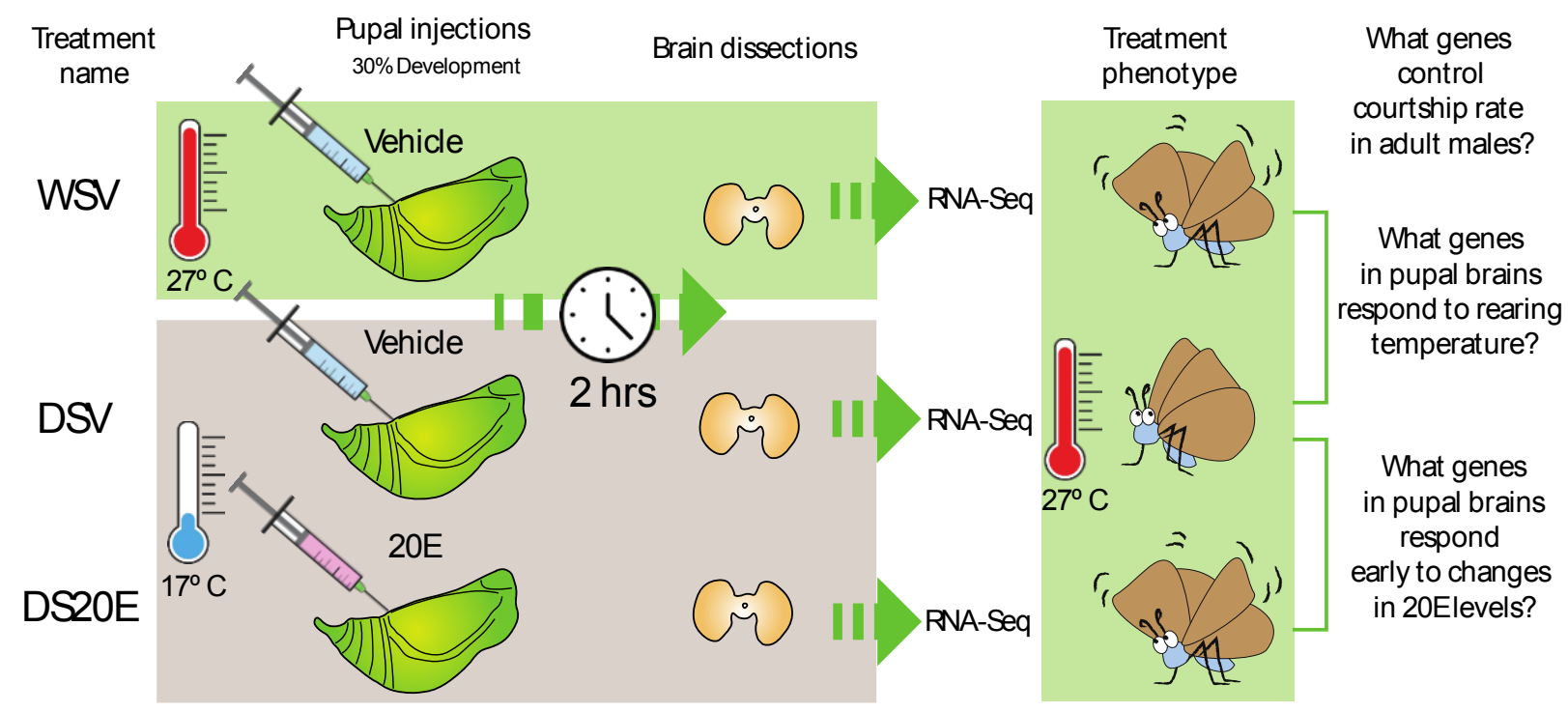

Fig. 1. Overview of the experimental set-up for the pupal injections, brain dissections and RNAseq for the three different treatment groups. 

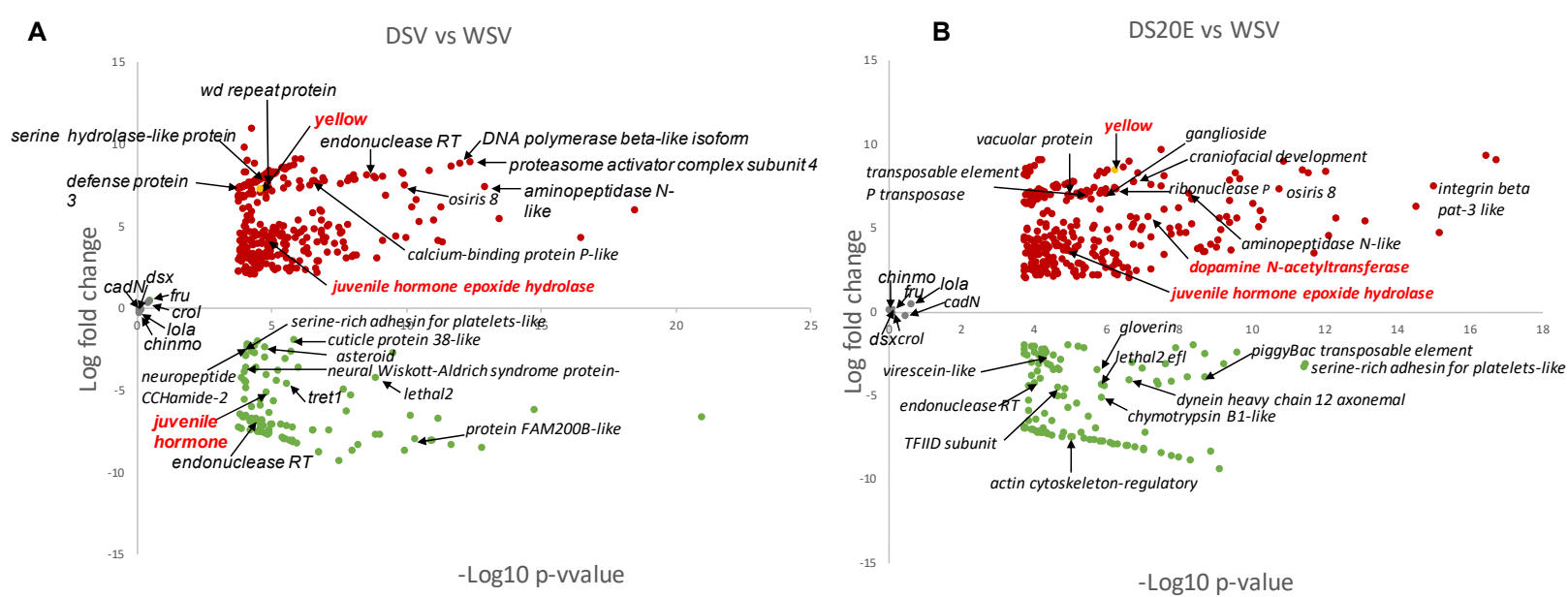

C

DS20E vs DSV

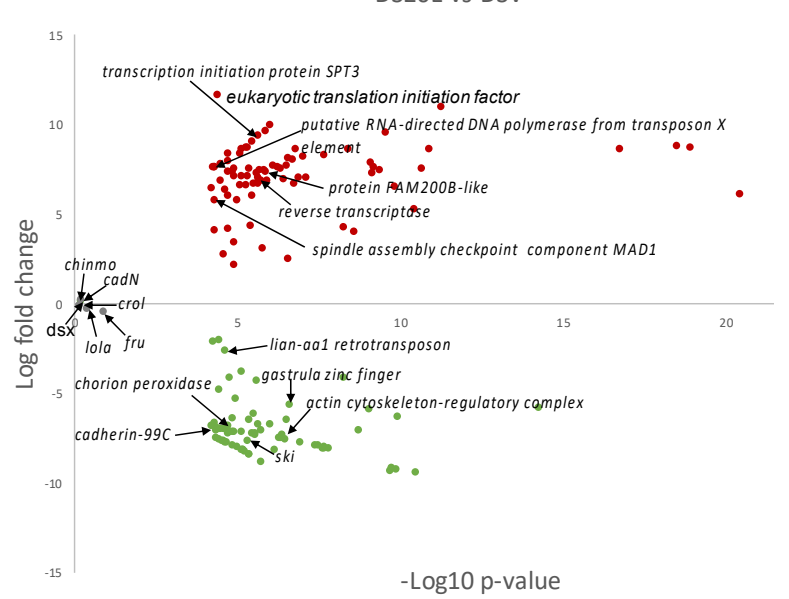

Fig. 2. Volcano plots summarizing the log-fold change values and p-values of the differentially expressed genes. Annotations are shown for the top 10 differentially expressed genes which returned hits using the software Blast2Go (blastx to NCBI). Dopamine N-acetyltransferase (AANAT) and Juvenile epoxide hydrolase are also shown although they were not in the top 10. Upregulated genes are shown in red and downregulated genes are shown in green. (A) shows genes up- and downregulated in brains from the dry season vehicle treatment compared to the wet season vehicle treatment (DSV vs WSV). (B) shows genes up and downregulated in brains from the DS20E treatment (dry season pupa injected with 20E) compared to the WSV treatment (DS20E vs WSV). (C) shows genes up- and downregulated in brains from the DS20E treatment compared to DSV (DS20E vs DSV). Genes involved in male courtship behavior in Drosophila that were not differentially expressed in any comparison (grey). 


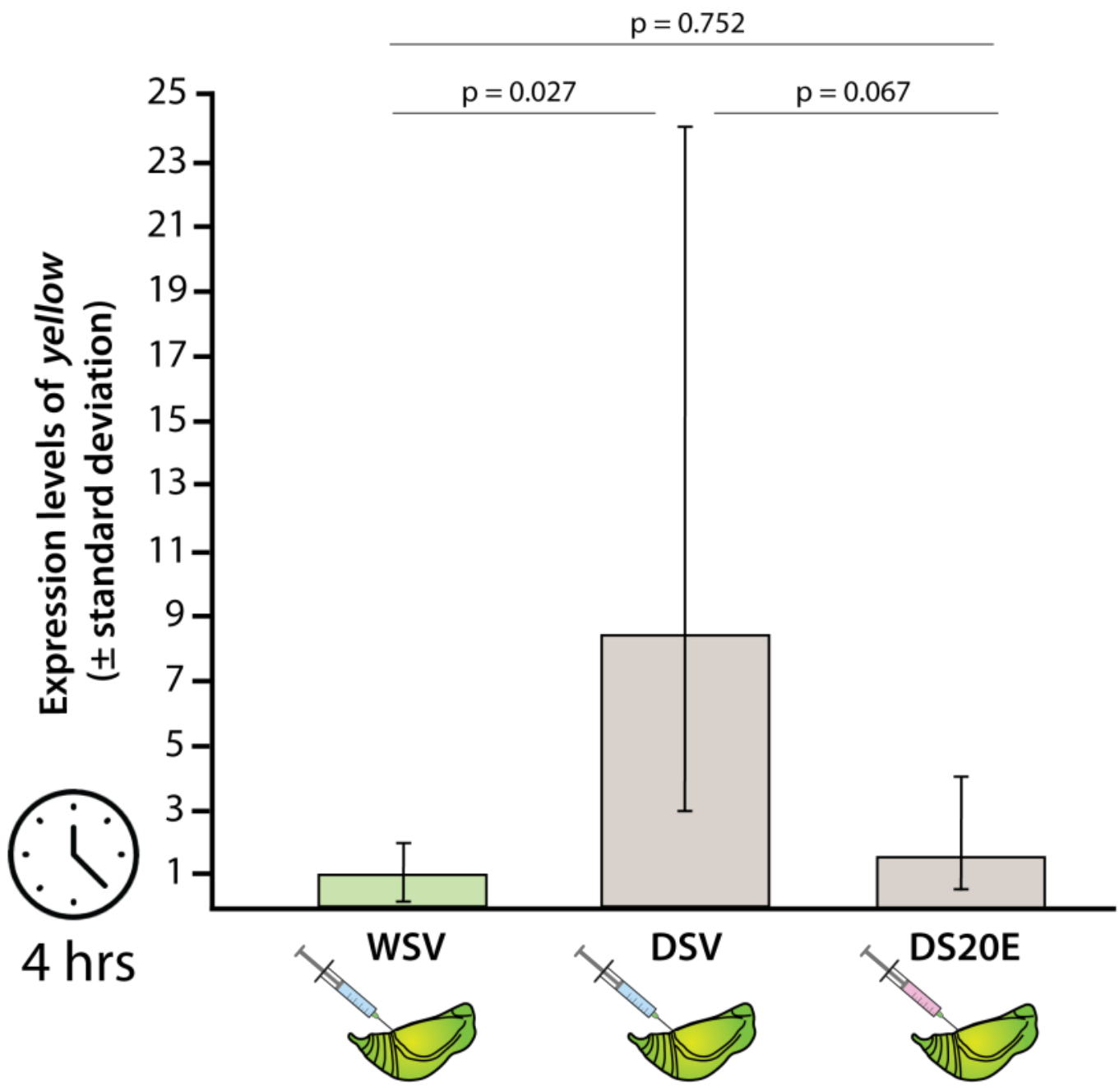

Fig. 3. Four hours after injections, yellow is downregulated in brains of DS pupae injected with $60120 \mathrm{E}$ compared to pupae injected with vehicle. Bars show fold change expression relative to WS 602 pupae injected with vehicle solution. Indicated $p$ values are the Turkey-adjusted $p$ values from 603 the post-hoc analysis.

604 
A

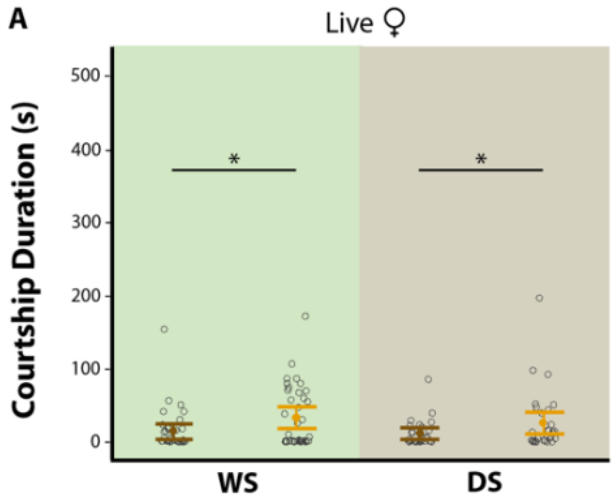

B

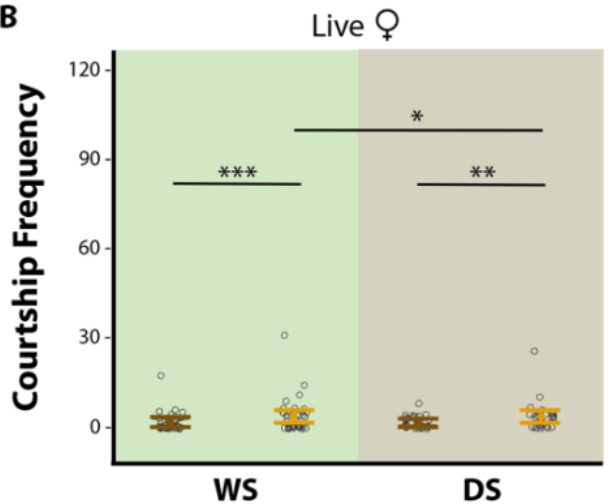

C

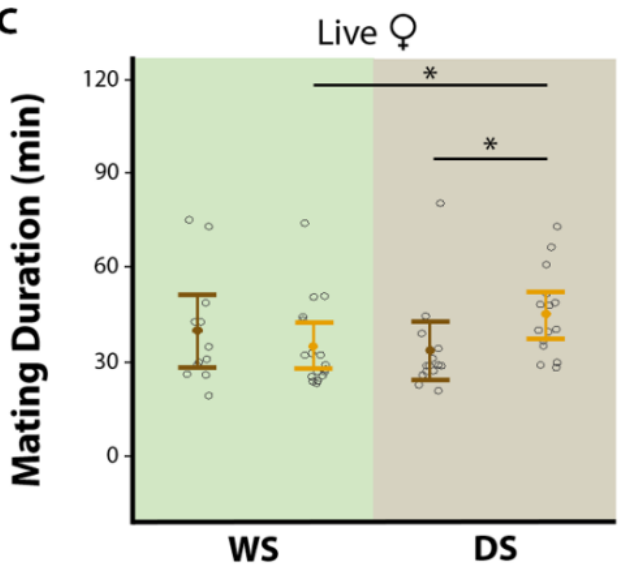

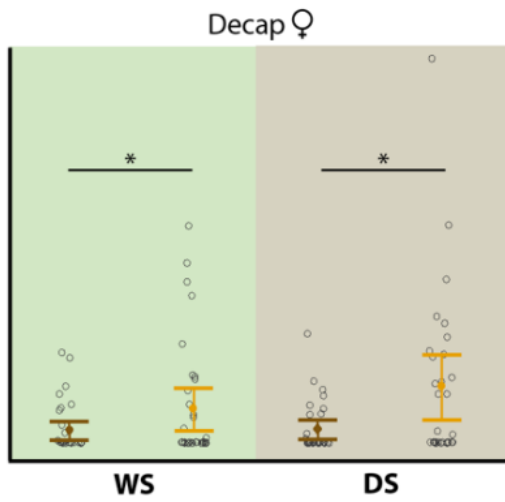

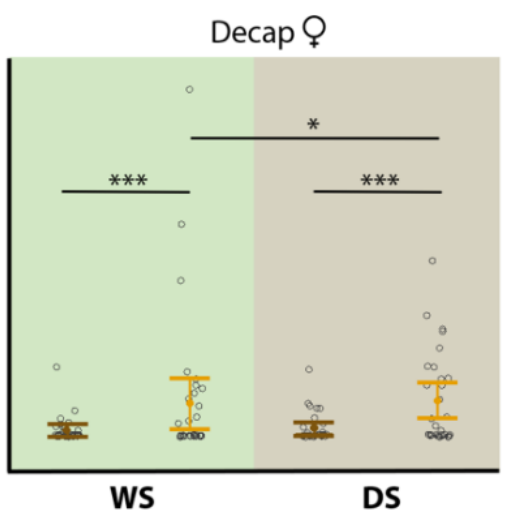

WS

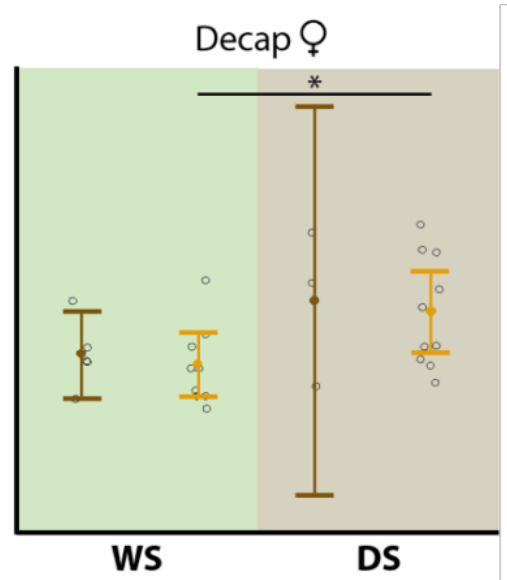

605

606

607

608

609

610

611

612

613

614

615

616

617
Fig. 4. Courtship behavior of Wt and Yellow males, for wet (WS) and dry (DS) seasonal forms, in both live and decapitation assays. Yellow males courted at a higher duration and frequency than Wt males, for both WS and DS forms. DS Yellow males courted at a higher frequency and remained in copula for a longer period of time than WS Yellow males. (A) Courtship duration, (B) Courtship frequency and (C) Mating duration were quantified. Mating duration was quantified among mated males only. Vertical bars represent $95 \%$ confidence intervals. Open circles $\left(^{\circ}\right)$ are data points. Asterisks $(*)$ indicate significant differences: ${ }^{*} \mathrm{p} \leq 0.05,{ }^{* *} \mathrm{p} \leq 0.01,{ }^{* * *} \mathrm{p} \leq 0.001$. Outliers are not removed as they are true measurements. n(WS-Live-Wt) and n(WS-Live-Yellow) $=38, \mathrm{n}(\mathrm{WS}-\mathrm{Decap}-\mathrm{Wt})$ and $\mathrm{n}(\mathrm{WS}-\mathrm{Decap}-$ Yellow $)=34, \mathrm{n}(\mathrm{DS}-$ Live-Wt $), \mathrm{n}(\mathrm{DS}-$ Live-Yellow $)$, $\mathrm{n}(\mathrm{DS}-\mathrm{Decap}-\mathrm{Wt})$ and $\mathrm{n}(\mathrm{DS}-\mathrm{Decap}-$ Yellow $)=30$. 


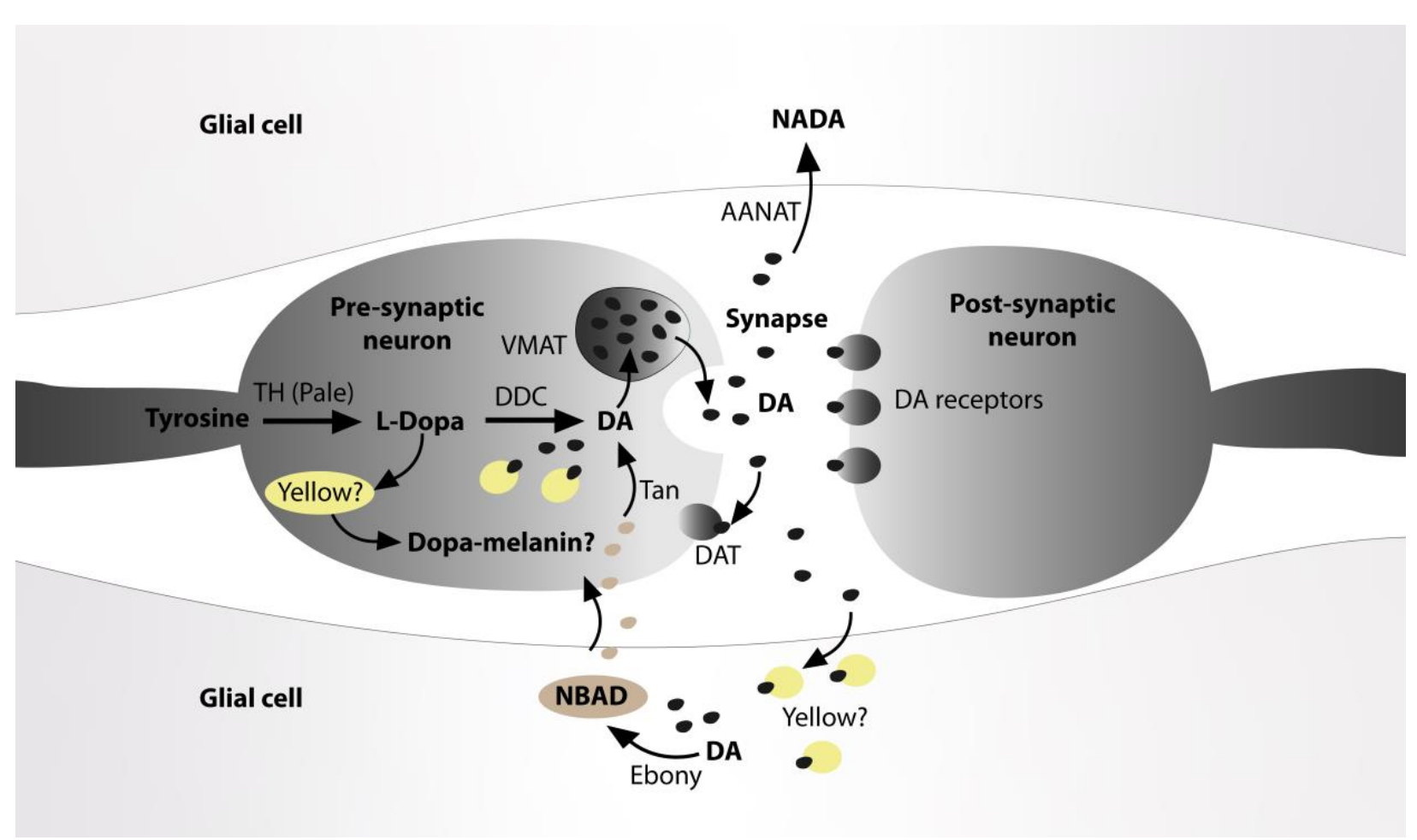

Fig. 5. Schematic model of a melanized dopaminergic neuron adapted from Yamamoto and Seto (36). In this model tyrosine is converted to L-Dopa which is converted to dopamine (DA) by Dopa decarboxylase (DDC). We hypothesize that yellow may also be expressed in dopaminergic neurons to convert L-Dopa to Dopa-melanin. Upregulation of yellow in DS pupal brains could decrease availability of L-Dopa to produce dopamine which is packaged into vesicles (VMAT) for release into the synapse. Another possibility is that Yellow binds to dopamine, reducing its availability either for direct synthesis of dopamine by DDC or indirectly (if it is also expressed in glial cells) by limiting the availability of dopamine conversion to NBAD by Ebony, which is converted back to dopamine by Tan. An excess of DA is converted to NADA by AANAT or is taken up by DAT back into the pre-synaptic neuron. 


\section{References}

633

634

635

636

637

638

639

640

641

642

643

644

645

646

647

648

649

650

651

652

653

654

655

656

657

658

659

660

661

662

663

664

665

666

667

668

669

670

671

672

673

674

675
1. J. K. Neal, J. Wade, Courtship and copulation in the adult male green anole: effects of season, hormone and female contact on reproductive behavior and morphology. Behav Brain Res 177, 177-185 (2007).

2. J. Meitzenn, C. K. Thompson, Seasonal-like growth and regression of the avian song control system- neural and behavioral plasticity in adult male Gambel's white-crowned sparrows. Gen Comp Endocrinol. 157, 259-265 (2008).

3. P. M. Forlano, J. A. Sisneros, K. N. Rohmann, A. H. Bass, Neuroendocrine control of seasonal plasticity in the auditory and vocal systems of fish. Front Neuroendocrinol 37, 129-145 (2015).

4. A. D. Tramontin, E. A. Brenowitz, Seasonal plasticity in the adult brain. Trends in Neurosciences 23, 251-258 (2000).

5. S. X. Zhang, E. H. Glantz, D. Rogulja, M. A. Crickmore, Hormonal control of motivational circuitry orchestrates the transition to sexuality in Drosophila. bioRxiv 10.1101/852335 (2019).

6. A. Bear, A. Monteiro, Both cell-autonomous mechanisms and hormones contribute to sexual development in vertebrates and insects. Bioessays 35, 725-732 (2013).

7. M. M. Elekonich, G. E. Robinson, Organizational and activational effects of hormones on insect behavior. Journal of Insect Physiology 46, 1509-1515 (2000).

8. K. Wallen, The Organizational Hypothesis: Reflections on the 50th anniversary of the publication of Phoenix, Goy, Gerall, and Young (1959). Horm Behav 55, 561-565 (2009).

9. K. Kimura, T. Hachiya, M. Koganezawa, T. Tazawa, D. Yamamoto, Fruitless and doublesex coordinate to generate male-specific neurons that can initiate courtship. Neuron 59, 759-769 (2008).

10. A. Pandey, G. Bloch, Juvenile hormone and ecdysteroids as major regulators of brain and behavior in bees. Current Opinion in Insect Science 12, 26-37 (2015).

11. H. H. Lin et al., Hormonal Modulation of Pheromone Detection Enhances Male Courtship Success. Neuron 90, 1272-1285 (2016).

12. L. Duportets, A. Maria, S. Vitecek, C. Gadenne, S. Debernard, Steroid hormone signaling is involved in the age-dependent behavioral response to sex pheromone in the adult male moth Agrotis ipsilon. Gen Comp Endocrinol 186, 58-66 (2013).

13. J. W. Truman, L. M. Riddiford, Hormonal Mechanisms Underlying Insect Behaviour. Advances in Insect Physiology 10, 297-352 (1974).

14. K. J. Argue, A. J. Yun, W. S. Neckameyer, Early manipulation of juvenile hormone has sexually dimorphic effects on mature adult behavior in Drosophila melanogaster. Horm Behav 64, 589-597 (2013).

15. A. Bear, A. Monteiro, Male courtship rate plasticity in the butterfly Bicyclus anynana is controlled by temperature experienced during the pupal and adult stages. PLoS One 8, e64061 (2013).

16. K. L. Prudic, C. Jeon, H. Cao, A. Monteiro, Developmental plasticity in sexual roles of butterfly species drives mutual sexual ornamentation. Science 331, 73-75 (2011).

17. A. Bear, K. L. Prudic, A. Monteiro, Steroid hormone signaling during development has a latent effect on adult male sexual behavior in the butterfly Bicyclus anynana. PLoS One 12, e0174403 (2017). 
676 18. M. D. Drapeau, A. Radovic, P. J. Wittkopp, A. D. Long, A gene necessary for normal male courtship, yellow, acts downstream of fruitless in the Drosophila melanogaster larval brain. J Neurobiol 55, 53-72 (2003).

19. J. H. Massey, D. Chung, I. Siwanowicz, D. L. Stern, P. J. Wittkopp, The yellow gene influences Drosophila male mating success through sex comb melanization. Elife 8 (2019).

683

684

685

20. E. Dion, A. Monteiro, J. Y. Yew, Phenotypic plasticity in sex pheromone production in Bicyclus anynana butterflies. Sci Rep 6, 39002 (2016).

21. W. Li, A. Godzik, Cd-hit: a fast program for clustering and comparing large sets of protein or nucleotide sequences. Bioinformatics 22, 1658-1659 (2006).

22. M. C. Neville et al., Male-specific fruitless isoforms target neurodevelopmental genes to specify a sexually dimorphic nervous system. Curr Biol 24, 229-241 (2014).

23. J. H. Massey, D. Chung, I. Siwanowicz, D. L. Stern, P. J. Wittkopp, The yellow gene influences Drosophila male mating success through sex comb melanization. eLife $\mathbf{8}$, e49388 (2019).

24. K. A. Robertson, A. Monteiro, Female Bicyclus anynana butterflies choose males on the basis of their dorsal UV-reflective eyespot pupils. Proc. R. Soc. B 272, 1541-1546

693 (2005).

694

25. M. Huq, S. Bhardwaj, A. Monteiro, Male Bicyclus anynana Butterflies Choose Females on the Basis of Their Ventral UV-Reflective Eyespot Centers. Journal of insect science (Online) 19, 25 (2019).

26. H. T. Spieth, Drosophilid mating behaviour- The behaviour of decapitated females. Animal Behaviour 14, 226-235 (1966).

27. J. M. Ringo, "Hormonal Regulation of Sexual Behavior in Insects" in Hormones, Brain and Behavior. (2002), pp. 93-114.

28. R. H. Barth, L. J. Lester, Neuro-hormonal control of sexual behavior in insects. Ann. Rev. Entomol. 18, 445-472 (1973).

29. H. Ishimoto, T. Sakai, T. Kitamoto, Ecdysone signaling regulates the formation of longterm courtship memory in adult Drosophila melanogaster. Proc Natl Acad Sci U S A 106, 6381-6386 (2009).

30. M. Bastock, A gene mutation which changes a behavior pattern. Evolution 10, 421-439 (1956).

31. M. D. Drapeau, S. A. Cyran, M. M. Viering, P. K. Geyer, A. D. Long, A cis-regulatory sequence within the yellow locus of Drosophila melanogaster required for normal male mating success. Genetics 172, 1009-1030 (2006).

32. R. Wilson, B. Burnet, L. Eastwood, K. Connolly, Behavioural pleiotropy of the yellow gene in Drosophila melanogaster. Genet Res 28, 75-88 (1976).

33. H. Verlinden, Dopamine signalling in locusts and other insects. Insect Biochem Mol Biol 97, 40-52 (2018).

34. E. Petruccelli, A. Lark, J. A. Mrkvicka, T. Kitamoto, Significance of DopEcR, a Gprotein coupled dopamine/ecdysteroid receptor, in physiological and behavioral response to stressors. J Neurogenet 34, 55-68 (2020). 
36. S. Yamamoto, E. S. Seto, Dopamine Dynamics and Signaling in Drosophila- An Overview of Genes, Drugs and Behavioral Paradigms. Pigment Cell and Melanoma Research 63, 107-119 (2014).

37. H. Barek, A. Veraksa, M. Sugumaran, Drosophila melanogaster has the enzymatic machinery to make the melanic component of neuromelanin. Pigment Cell Melanoma Res 31, 683-692 (2018).

38. P. J. Wittkopp, J. R. True, S. B. Carroll, Reciprocal functions of the Drosophila yellow and ebony proteins in the development and evolution of pigment patterns. Developmental neurobiology 129, 1849-1858 (2002).

39. J. Li, B. M. Christensen, Biological Function of Insect Yellow Gene Family. T. Liu, LeKang, Eds., Recent Advances in Entomological Research From Molecular Biology to Pest Management. (Springer, 2011).

40. X. Xu et al., Structure and function of a "yellow" protein from saliva of the sand fly Lutzomyia longipalpis that confers protective immunity against Leishmania major infection. J Biol Chem 286, 32383-32393 (2011).

41. I. Y. Rauschenbach et al., Mechanisms of age-specific regulation of dopamine metabolism by juvenile hormone and 20-hydroxyecdysone in Drosophila females. $J$ Comp Physiol B 181, 19-26 (2011).

42. B. Zilberman-Peled, B. Ron, A. Gross, J. P. Finberg, Y. Gothilf, A possible new role for fish retinal serotonin-N-acetyltransferase-1 (AANAT1): Dopamine metabolism. Brain Res 1073-1074, 220-228 (2006).

43. I. Y. Rauschenbach et al., Dopamine effect on 20-hydroxyecdysone level is mediated by juvenile hormone in Drosophila females. Dokl Biochem Biophys 446, 263-265 (2012).

44. L. L. Ellis, G. E. Carney, Mating alters gene expression patterns in Drosophila melanogaster male heads. BMC Genomics 11, 558 (2010).

45. N. E. Gruntenko et al., An increase in the dopamine level accelerates sexual maturation of Drosophila melanogaster deficient in the juvenile hormone. Dokl Biol Sci 406, 88-90 (2006).

46. K. Harano, K. Sasaki, T. Nagao, M. Sasaki, Influence of age and juvenile hormone on brain dopamine level in male honeybee (Apis mellifera): association with reproductive maturation. J Insect Physiol 54, 848-853 (2008).

47. N. E. Gruntenko, E. K. Karpova, N. A. Chentsova, N. V. Adonyeva, I. Y. Rauschenbach, 20-hydroxyecdysone and juvenile hormone influence tyrosine hydroxylase activity in Drosophila females under normal and heat stress conditions. Arch Insect Biochem Physiol 72, 263-272 (2009).

48. F. D. Karim, G. M. Guild, C. S. Thummel, The Drosophila Broad-Complex plays a key role in controlling ecdysone-regulated gene expression at the onset of metamorphosis. . Development 118, 977-988 (1993).

49. Z. Gauhar et al., Genomic mapping of binding regions for the Ecdysone receptor protein complex. Genome Res 19, 1006-1013 (2009).

50. A. M. Bolger, M. Lohse, B. Usadel, Trimmomatic: a flexible trimmer for Illumina sequence data. Bioinformatics 30, 2114-2120 (2014).

51. M. G. Grabherr et al., Full-length transcriptome assembly from RNA-Seq data without a reference genome. Nat. Biotechnol. 29, 644-652 (2011).

52. B. J. Haas et al., De novo transcript sequence reconstruction from RNA-seq using the Trinity platform for reference generation and analysis. Nat Protoc 8, 1494-1512 (2013). 
53. B. Li, C. N. Dewey, RSEM: accurate transcript quantification from RNA-Seq data with or without a reference genome. BMC Bioinformatics 12, 323 (2011).

54. B. Langmead, C. Trapnell, M. Pop, S. L. Salzberg, Ultrafast and memory-efficient alignment of short DNA sequences to the human genome. Genome Biology 10, R25 (2009).

55. M. Robinson, D. McCarthy, G. Smyth, edgeR: a Bioconductor package for differential expression analysis of digital gene expression data. Bioinformatics 26, 139-140 (2010).

56. R. W. Nowell et al., A high-coverage draft genome of the mycalesine butterfly Bicyclus anynana. GigaScience 6, 1-7 (2017).

57. Q. Zhang et al., TqPCR: A Touchdown qPCR Assay with Significantly Improved Detection Sensitivity and Amplification Efficiency of SYBR Green qPCR. PLOS ONE 10, e0132666 (2015).

58. M. T. Ganger, G. D. Dietz, S. J. Ewing, A common base method for analysis of qPCR data and the application of simple blocking in qPCR experiments. BMC Bioinformatics 18, 534 (2017).

59. R Development Core Team (2020) R: A language and environment for statistical computing. ed R. F. f. S. Computing (ISBN 3-900051-07-0, Vienna, Austria).

60. RStudio Team (2020) RStudio: Integrated Development for R. http://www.rstudio.com/. ed R. Inc. (Boston, MA).

61. R. M. Hope (2013) Rmisc: Ryan Miscellaneous. R package version 1.5. .

62. J. Fox, S. Weisberg, An $\{R\}$ Companion to Applied Regression, Third Edition. T. O. C. Sage, Ed. (2019).

63. R. V. Lenth, emmeans: Estimated Marginal Means, aka Least-Squares Means. R package version 1.4.6., 1 (2020).

64. H. Miura, R. M. Quadros, C. B. Gurumurthy, M. Ohtsuka, Easi-CRISPR for creating knock-in and conditional knockout mouse models using long ssDNA donors. Nat Protoc 13, 195-215 (2018).

65. F. Mery et al., Public versus personal information for mate copying in an invertebrate. Curr. Biol. 19, 730-734 (2009).

66. C. M. Nieberding et al., The male sex pheromone of the butterfly Bicyclus anynana: towards an evolutionary analysis Plos ONE 3, e2751 (2008).

67. P. K. Dunn, Tweedie: Evaluation of Tweedie exponential family models. R package version 2.3. (2017).

68. S. Jackman, pscl: Classes and Methods for R Developed in the Political Science Computational Laboratory, R package version 1.5.5. United States Studies Centre, University of Sydney, Sydney, New South Wales, Australia. (2020).

69. R. Maia, C. M. Eliason, P.-P. Bitton, S. M. Doucet, M. D. Shawkey, pavo: an R Package for the analysis, visualization and organization of spectral data. Methods in Ecology and Evolution 4, 609-613 (2013). 
bioRxiv preprint doi: https://doi.org/10.1101/2021.06.13.448264; this version posted June 14, 2021. The copyright holder for this preprint (which was not certified by peer review) is the author/funder, who has granted bioRxiv a license to display the preprint in perpetuity. It is made available under aCC-BY-NC-ND 4.0 International license.

\section{Supplementary data and information}

\section{Supplementary tables}

Table S1. Assembly statistics for B. anynana brain transcriptome

Type

Assembly statistics

Total Trinity genes

689,657

Total Trinity transcripts

$1,403,420$

Percent GC

36.50

Median contig length (bp)

456

Average contig length (bp)

703.17

N50 (bp)

973

Total assembled bases

$986,848,704$ 
bioRxiv preprint doi: https://doi.org/10.1101/2021.06.13.448264; this version posted June 14, 2021. The copyright holder for this preprint (which was not certified by peer review) is the author/funder, who has granted bioRxiv a license to display the preprint in perpetuity. It is made

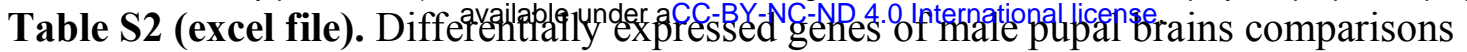

between treatments (Dry season with vehicle - DSV, Wet season with vehicle - WSV and Dry season injected with 20E - DS20E. $\log$ FC represents the log-foldchange in the gene

expression; $\log C \mathrm{PM}$ represents the log counts per million; FDR represents the false discovery rate, where values of less than 0.001 are simply represented as $<0.001$. See excel file sheet 1 for DSV compared to WSV, sheet 2 for DS20E compared to DSV, and sheet 3 for DS20E compared to WSV. Green color indicates down-regulated genes and red indicates upregulated genes. 
bioRxiv preprint doi: https://doi.org/10.1101/2021.06.13.448264; this version posted June 14, 2021. The copyright holder for this preprint (which was not certified by peer review) is the author/funder, who has granted bioRxiv a license to display the preprint in perpetuity. It is made

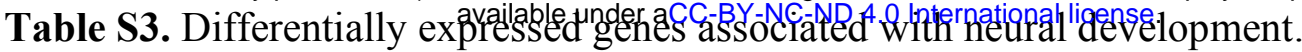

\begin{tabular}{|c|c|c|}
\hline Genes & Function & References \\
\hline asteroid & $\begin{array}{l}\text { Involved in the epidermal growth factor } \\
\text { receptor signaling pathway in Drosophila and } \\
\text { could affect the differentiation of photoreceptor } \\
\text { cells in eye development. } \\
\text { Asteroid is also crucial for the specification of } \\
\text { muscle tissues. }\end{array}$ & $\begin{array}{l}\text { Higson, Tessiatore et al. (1993), } \\
\text { Kotarski, Leonard et al. (1998), } \\
\text { Ruden, Wang et al. (1999), Artero, } \\
\text { Furlong et al. (2003) }\end{array}$ \\
\hline $\begin{array}{l}\text { Integrin beta } \\
\text { pat- } 3, \beta P S\end{array}$ & $\begin{array}{l}\text { Integrins are a large family of transmembrane } \\
\text { molecules that mediate cell and extracellular } \\
\text { matrix interactions, ubiquitous in multicellular } \\
\text { animals In Drosophila, integrins are essential } \\
\text { for normal gonad development. } \beta P S \text { plays a } \\
\text { role in eye development at the late pupal stage } \\
\text { for photoreceptor cell organization. }\end{array}$ & $\begin{array}{l}\text { Reviewed by Johnson, Lu et al. } \\
\text { (2009), Chen, Lewallen et al. } \\
\text { (2013)). Tanentzapf, Devenport et } \\
\text { al. (2007), O'Reilly, Lee et al. (2008) } \\
\text { Zusman, Patel-King et al. (1990), } \\
\text { Zusman, Grinblat et al. (1993) }\end{array}$ \\
\hline $\begin{array}{l}\text { Lactoylglutathione } \\
\text { lyase, Glo1 }\end{array}$ & $\begin{array}{l}\text { Part of the glyoxalase system present in the } \\
\text { cytosol of all cells and catalyzes the } \\
\text { detoxification of methylglyoxal, a by-product of } \\
\text { metabolism. Methylglyoxal (MG) inhibits cell } \\
\text { division in a range of organisms by interfering } \\
\text { with protein, DNA and RNA synthesis and can } \\
\text { lead to the damage of cells through the } \\
\text { production of precursors that react with } \\
\text { intracellular and extracellular proteins. The } \\
\text { effect of Glo1 expression on behavior was } \\
\text { studied in male mice, where higher expression } \\
\text { of Glo1 was associated with less locomotor } \\
\text { activity in mice with Glo1 knockout mice } \\
\text { moving and exploring significantly more than } \\
\text { wildtype mice. }\end{array}$ & $\begin{array}{l}\text { Reviewed by Thornalley (2003) } \\
\text { Együd and Szent-Györgyi (1966), } \\
\text { Együd and Szent-Györgyi (1966), } \\
\text { Krymkiewicz, Diéguez et al. (1971), } \\
\text { Brownlee (2001) Williams, Lim et al. } \\
\text { (2009), Jang, Kwon et al. (2017) }\end{array}$ \\
\hline $\begin{array}{l}\text { lethal } 2 \text { essential } \\
\text { for life, (I(2)efl) }\end{array}$ & $\begin{array}{l}\text { Involved in neurite extension and synapse } \\
\text { morphology, I(2)efl expression is upregulated } \\
\text { in the brains of older bees, a finding that has } \\
\text { been replicated in other studies comparing } \\
\text { foragers and nurse bees I(2)efl may be } \\
\text { required for behavioral maturation of adult } \\
\text { workers and also neural plasticity as it was } \\
\text { upregulated in honeybees exposed to light. }\end{array}$ & $\begin{array}{l}\text { Becker, Kucharski et al. (2016) } \\
\text { Kucharski and Maleszka (2002), } \\
\text { Garcia, Saraiva Garcia et al. (2009). }\end{array}$ \\
\hline $\begin{array}{l}\text { neural Wiskott- } \\
\text { Aldrich syndrome } \\
\text { protein (N-WASP) }\end{array}$ & $\begin{array}{l}\text { Involved in the organization of actin } \\
\text { cytoskeleton and neurite outgrowth. }\end{array}$ & Suetsugu, Hattori et al. (2002) \\
\hline $\begin{array}{l}\text { neuropeptide } \\
\text { CCHamide2 }\end{array}$ & $\begin{array}{l}\text { Produced in both the midgut and the brain. } \\
\text { CRISPR mutants of CCHamide2 show } \\
\text { reductions in feeding, delayed larval } \\
\text { development, smaller wings and reduced adult } \\
\text { locomotor activity during foraging hours }\end{array}$ & Ren, Hauser et al. (2015) \\
\hline osiris genes & $\begin{array}{l}\text { Essential housekeeping functions. Osiris } \\
\text { genes have been associated with pathogen } \\
\text { response, developmental stage and the } \\
\text { degree of melanisation. }\end{array}$ & $\begin{array}{l}\text { Dorer, Rudnick et al. (2003), Shah, } \\
\text { Dorer et al. (2012), Cornman, Lopez } \\
\text { et al. (2013), McTaggart, Hannah et } \\
\text { al. (2015), Wu, Tong et al. (2016), } \\
\text { Yang, Huang et al. (2016), Andrade } \\
\text { López, Lanno et al. (2017) }\end{array}$ \\
\hline $\begin{array}{l}\text { SKI family } \\
\text { transcriptional } \\
\text { corepressor } 2\end{array}$ & $\begin{array}{l}\text { SKOR2 is expressed in human and murine } \\
\text { neuronal tissues in embryogenesis and also } \\
\text { adult tissues }\end{array}$ & $\begin{array}{l}\text { (Arndt, Poser et al. 2005, Mizuhara, } \\
\text { Nakatani et al. 2005, Minaki, } \\
\text { Nakatani et al. 2008, Wang, } \\
\text { Harrison et al. 2011, Nakatani, } \\
\text { Minaki et al. 2014) }\end{array}$ \\
\hline
\end{tabular}


bioRxiv preprint doi: https://doi.org/10.1101/2021.06.13.448264; this version posted June 14, 2021. The copyright holder for this preprint (which was not certified by peer review) is the author/funder, who has granted bioRxiv a license to display the preprint in perpetuity. It is made

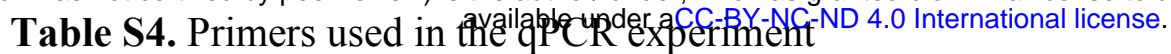

\begin{tabular}{|c|c|}
\hline Gene & Primers \\
\hline Elongation Factor- $1 \alpha$ & Forward: 5'- GTGGGCGTCAACAAAATGGA-3' \\
\hline$(\mathrm{EF}-1 \alpha)$ & Reverse: 3'- GCAAAAACAACGAT-5' \\
\hline \multirow[t]{2}{*}{ yellow } & Forward: 5' - TATACCTCTGGATGCGCCCT-3' \\
\hline & Reverse: 3'- AGAGTAAGGACAAACATTCGTCACA-5' \\
\hline
\end{tabular}


bioRxiv preprint doi: https://doi.org/10.1101/2021.06.13.448264; this version posted June 14, 2021. The copyright holder for this preprint (which was not certified by peer review) is the author/funder, who has granted bioRxiv a license to display the preprint in perpetuity. It is made

Supplementary Figures

Fig. S1. Summary of N50 contig lengths against ExN50 values

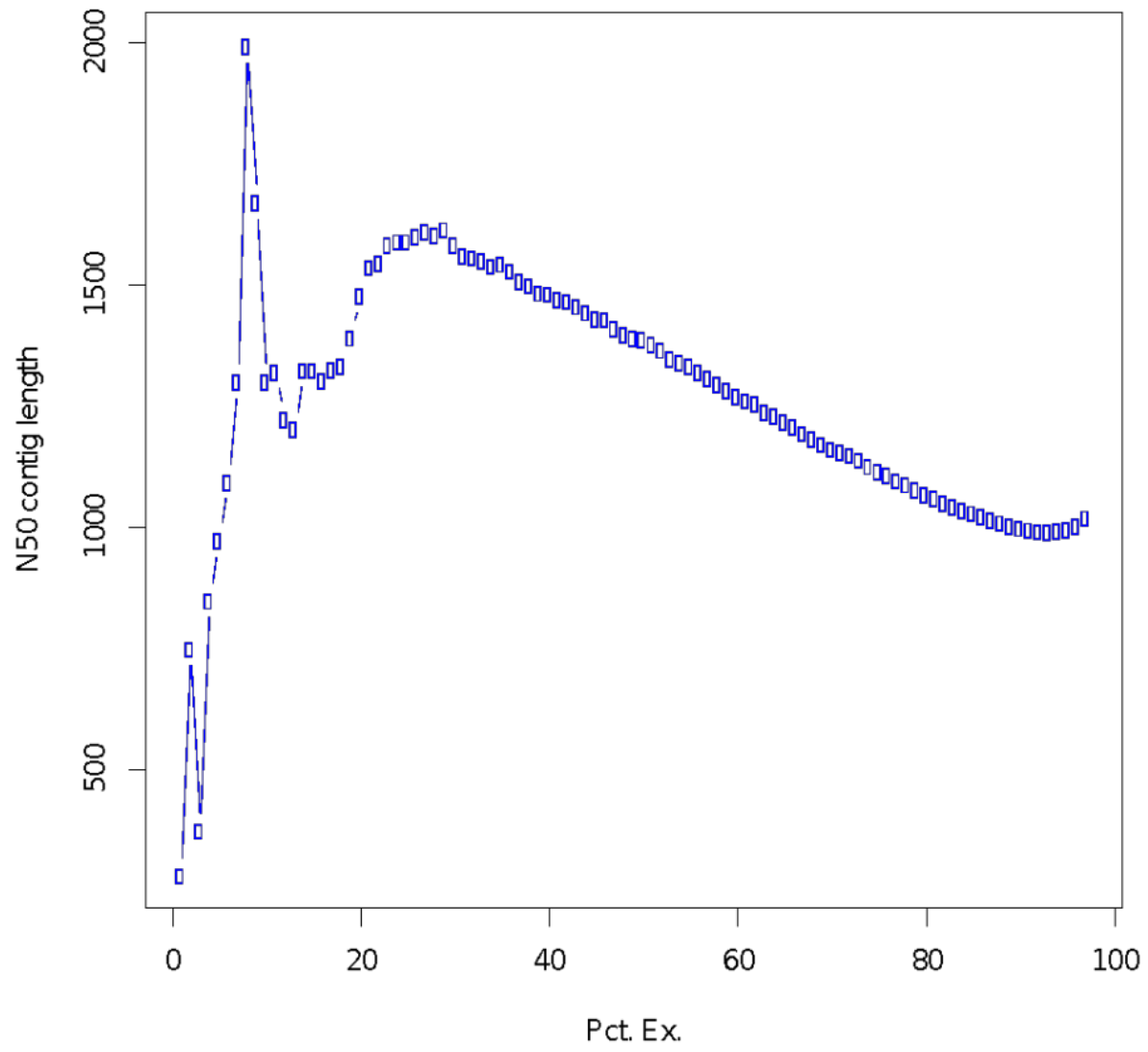


bioRxiv preprint doi: https://doi.org/10.1101/2021.06.13.448264; this version posted June 14, 2021. The copyright holder for this preprint (which was not certified by peer review) is the author/funder, who has granted bioRxiv a license to display the preprint in perpetuity. It is made

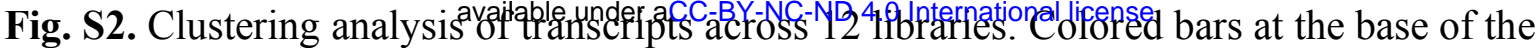
dendrogram indicate libraries of the three treatments - blue bar: wet season (S1, S12, S17); red bar: dry season with 20E (S2, S3, S6, S8, S15) and green bar: dry season (S4, S5, S7, S9). Dendrogram on the left represents the clustering of transcript expression based on the frequency of their expression together. The color of transcripts indicates their relative expression. The color key indicates the range of colors representing the fold change difference in expression.

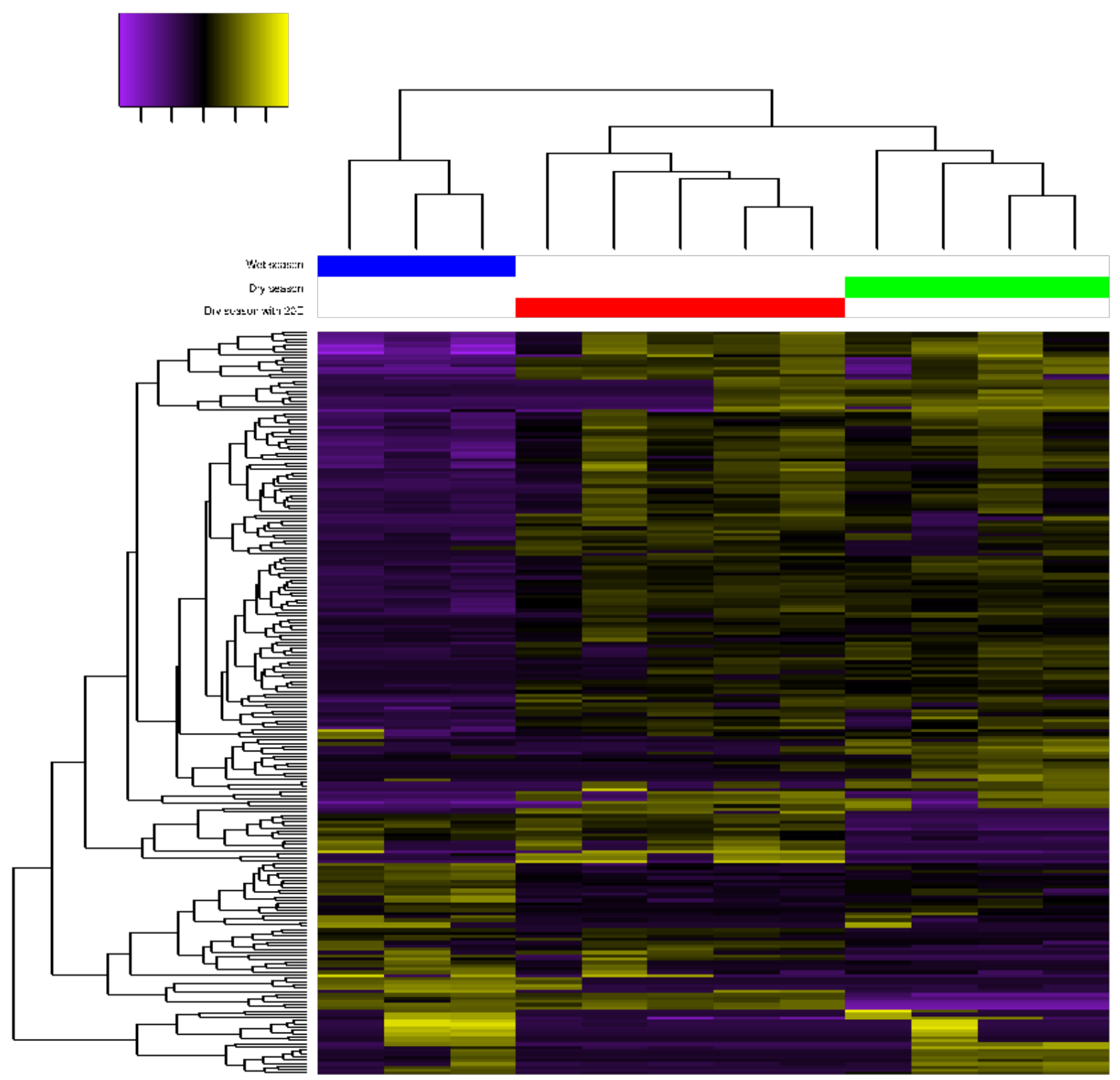


bioRxiv preprint doi: https://doi.org/10.1101/2021.06.13.448264; this version posted June 14, 2021. The copyright holder for this preprint (which was not certified by peer review) is the author/funder, who has granted bioRxiv a license to display the preprint in perpetuity. It is made

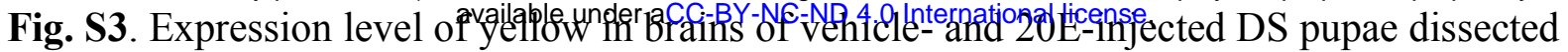
2 hours, 4 hours and 24 hours after injections. Levels of expression are calculated relative to the baseline groups, all WS pupae injected with vehicle solution (at the value of 1 , from 5 biological replicates at $2 \mathrm{~h}$ and 4 replicates at 4 and $24 \mathrm{~h}$ ) and dissected at the same time as DS individuals ( 5 biological replicates in all DS groups). Indicated $p$ are the Tukey adjusted $p$ values from the post-hoc analysis).
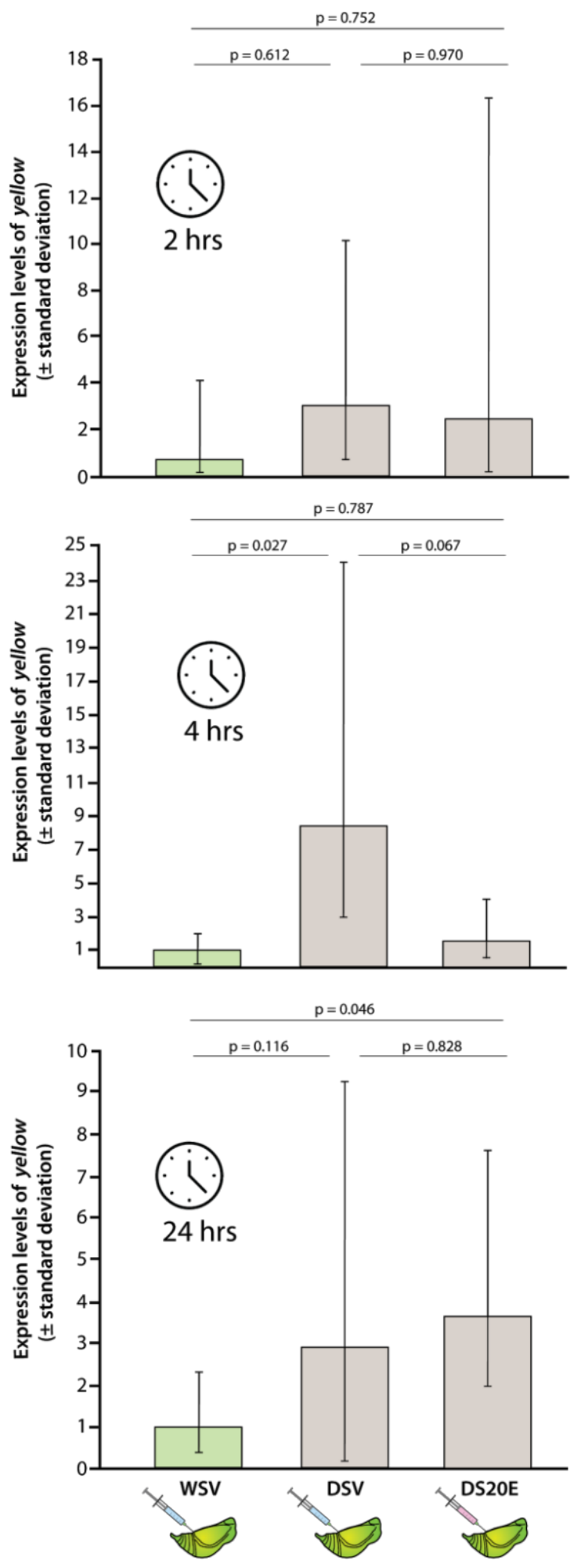
bioRxiv preprint doi: https://doi.org/10.1101/2021.06.13.448264; this version posted June 14, 2021. The copyright holder for this preprint (which was not certified by peer review) is the author/funder, who has granted bioRxiv a license to display the preprint in perpetuity. It is made

Fig. S4. Experimental design of the live (a-b) and decapitation (c-d) experiments. Two males and two females (live or decapitated) were put in one cage and left under UV light for one hour of observation. Quantification of courtship begins once the UV light is switched on, until the mating of individual butterflies. (a) Two Wt males and two Wt females; (b) two Yellow males and two Wt females; (c) two Wt males and two decapitated Wt females; (d) two Yellow males and two decapitated Wt females. These were done on wet season (WS) and dry season (DS) butterflies.
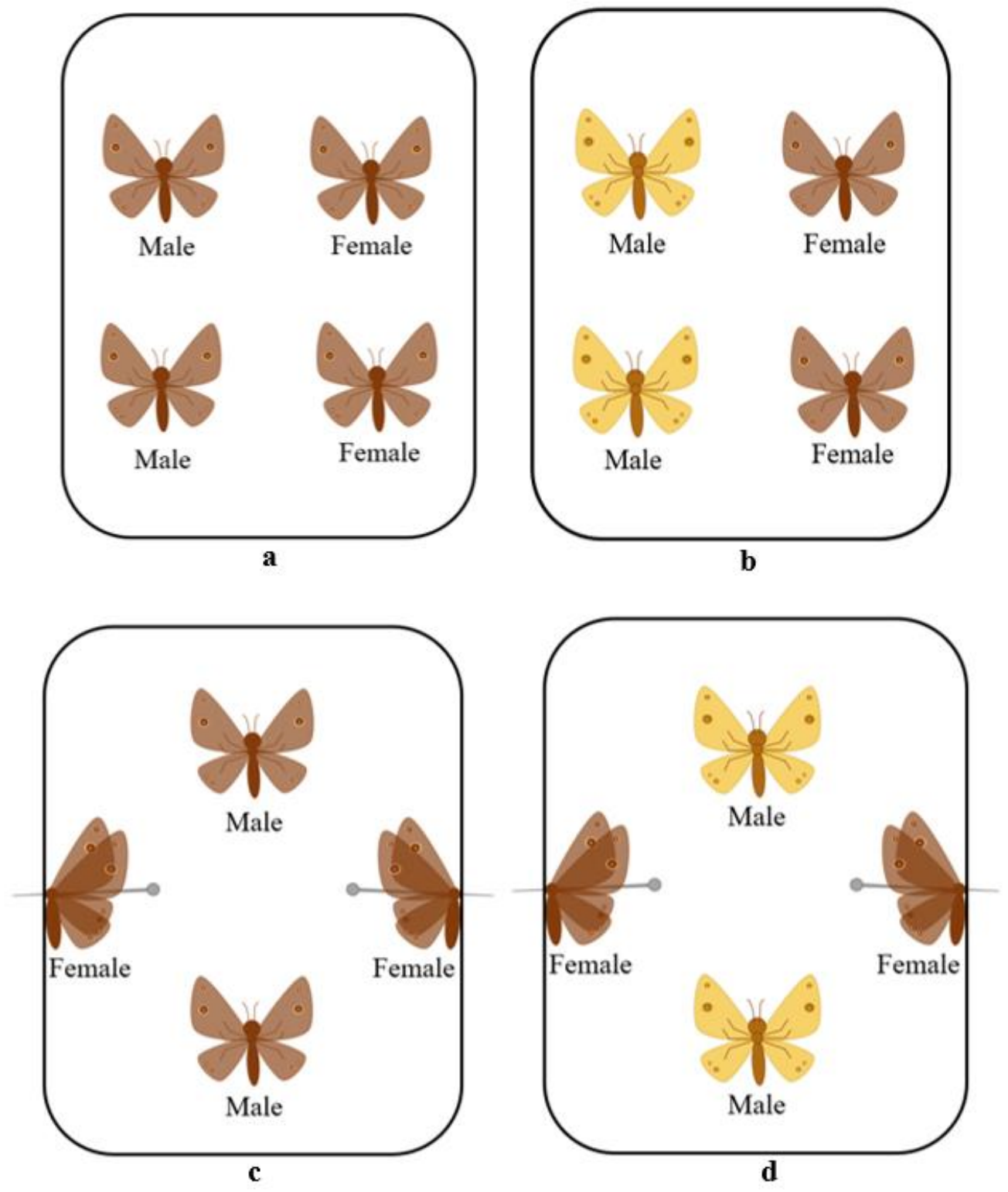
bioRxiv preprint doi: https://doi.org/10.1101/2021.06.13.448264; this version posted June 14, 2021. The copyright holder for this preprint (which was not certified by peer review) is the author/funder, who has granted bioRxiv a license to display the preprint in perpetuity. It is made

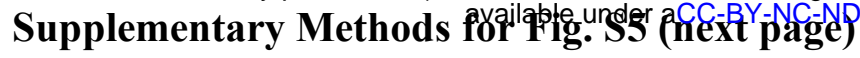

\section{UV photography and spectrophotometry}

To measure the UV reflectivity of the Yellow mutant and Wt male forewing eyespots on both the ventral and dorsal sides (Fig. S5), WS butterflies were photographed using a Nikon D7100 digital camera with a Jenoptik CoastalOpt $105 \mathrm{~mm}$ UV - Vis crystal lens under sunlight. Visible light was captured through a Baader UV/IR Cut Filter (transmits 400 to $680 \mathrm{~nm}$ ) and UV images were taken through a Baader U-Venus Filter (transmits 320 to $380 \mathrm{~nm}$ ). The camera settings were ISO100 and a shutter speed of 1/320 seconds for visible light and 10 seconds for UV light.

Scale reflectance was measured at the two forewing eyespots using a gonio-spectrophotometer and the accompanying program, OceanView 1.6.7 (Ocean Optics). Each measurement was taken with the axis of the illuminating and detecting fibre directed at a $20^{\circ}$ angle to the plane of the wing at a using a deuterium-halogen tungsten lamp (DH-2000, Ocean Optics) as a standardized light source and calibrated using a white Ocean Optics WS-1 reflectance standard. from the right forewing. A total of three replicates were done for each type and sex. 
bioRxiv preprint doi: https://doi.org/10.1101/2021.06.13.448264; this version posted June 14, 2021. The copyright holder for this preprint (which was not certified by peer review) is the author/funder, who has granted bioRxiv a license to display the preprint in perpetuity. It is made

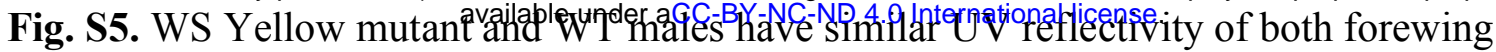
eyespots on both sides of the wing. (A) shows both the dorsal (left) and ventral (right) sides of a Wt butterfly, M1 and Cu1 eyespots are indicated by red and yellow squares respectively. Graphs show the mean smoothed reflectance spectra ( \pm standard deviation, $n=3$ ) of WS Yellow mutant and Wt butterflies $(280-400 \mathrm{~nm})$. The legend for each graph is shown on the bottom right: yellow - Yellow mutant $\mathrm{Cu} 1$, orange - Yellow mutant M1, brown - Wt Cu1, red - Wt M1. (B) Male Yellow and Wt B. anynana, dorsal Cu1 and M1; (C) Male Yellow and Wt B. anynana, ventral $\mathrm{Cu} 1$ and $\mathrm{M} 1$.

A
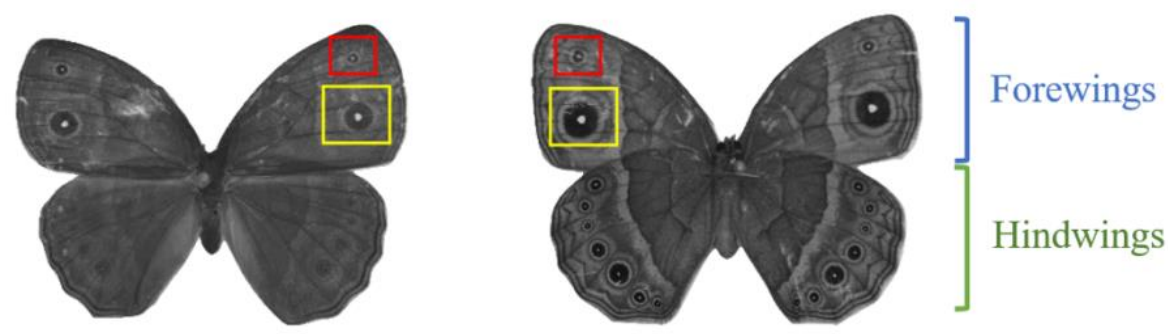

B

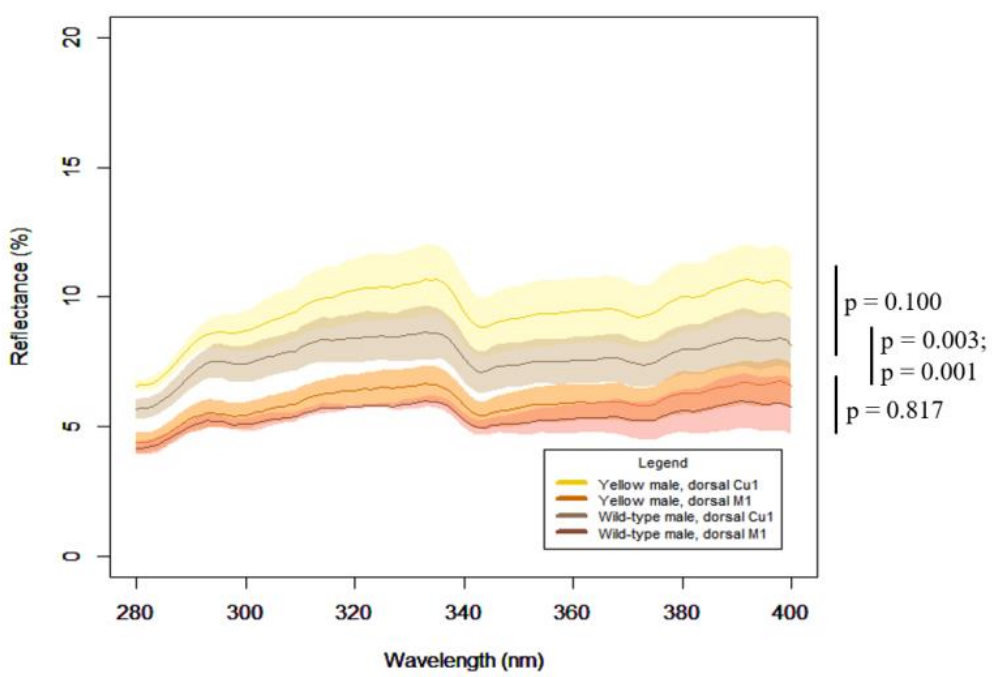

C

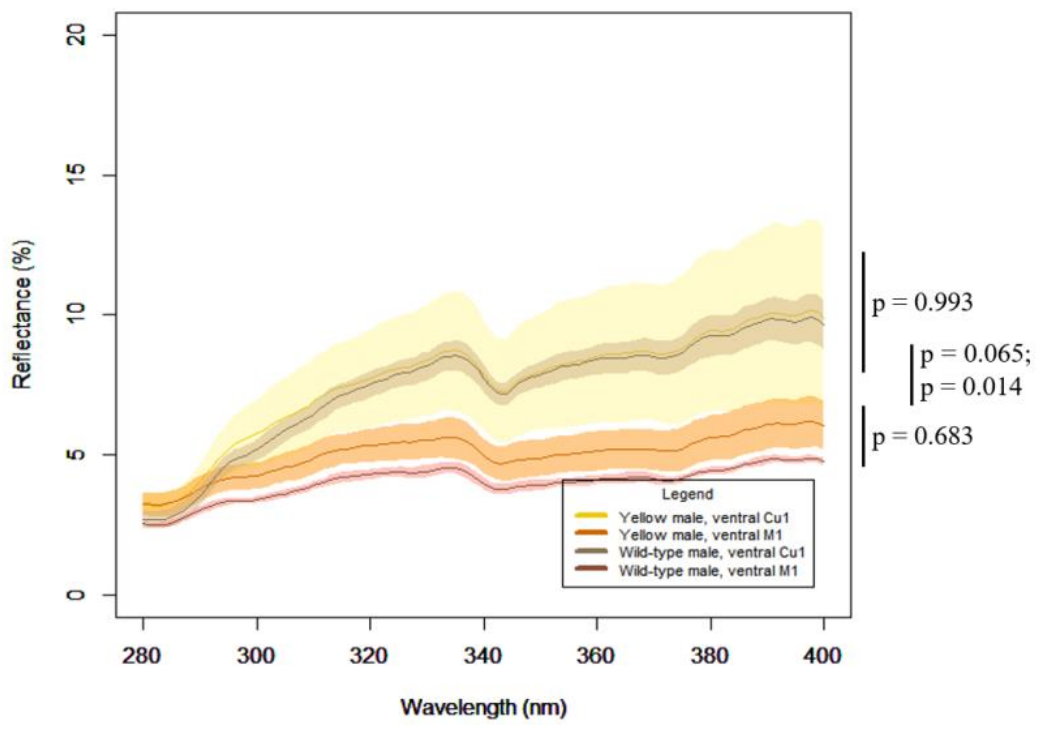


bioRxiv preprint doi: https://doi.org/10.1101/2021.06.13.448264; this version posted June 14, 2021. The copyright holder for this preprint (which was not certified by peer review) is the author/funder, who has granted bioRxiv a license to display the preprint in perpetuity. It is made

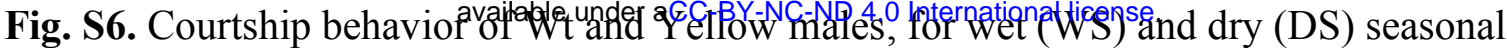
forms, in both live and decapitation assays. (A) Latency to mate and (B) Percentage of matings were quantified among mated males only. Vertical bars represent $95 \%$ confidence intervals. Open circles $\left({ }^{\circ}\right)$ are data points. Asterisks $(*)$ indicate significant differences: $* p \leq$ $0.05, * * p \leq 0.01, * * * p \leq 0.001$. Outliers are not removed as they are true measurements. $\mathrm{n}(\mathrm{WS}-$ Live-Wt) and $\mathrm{n}(\mathrm{WS}-$ Live-Yellow $)=38, \mathrm{n}(\mathrm{WS}$-Decap-Wt) and $\mathrm{n}$ (WS-Decap-Yellow) $=34, \mathrm{n}(\mathrm{DS}-\mathrm{Live}-\mathrm{Wt}), \mathrm{n}(\mathrm{DS}-\mathrm{Live}-Y$ ellow $), \mathrm{n}(\mathrm{DS}-\mathrm{Decap}-\mathrm{Wt})$ and $\mathrm{n}(\mathrm{DS}-\mathrm{Decap}-$ Yellow $)=30$.

A

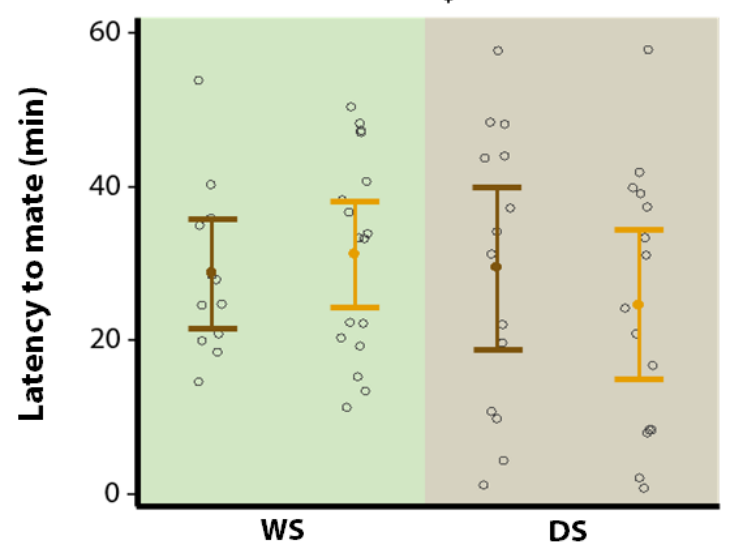

B

B
Live Q

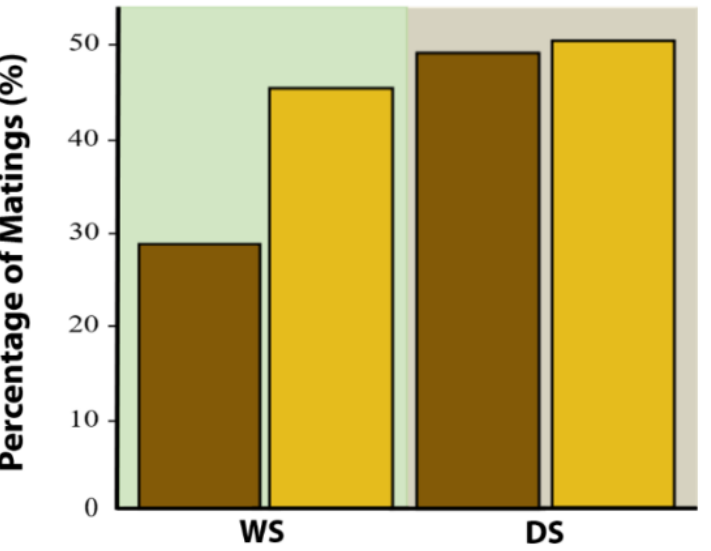

Decap $\bigcirc$

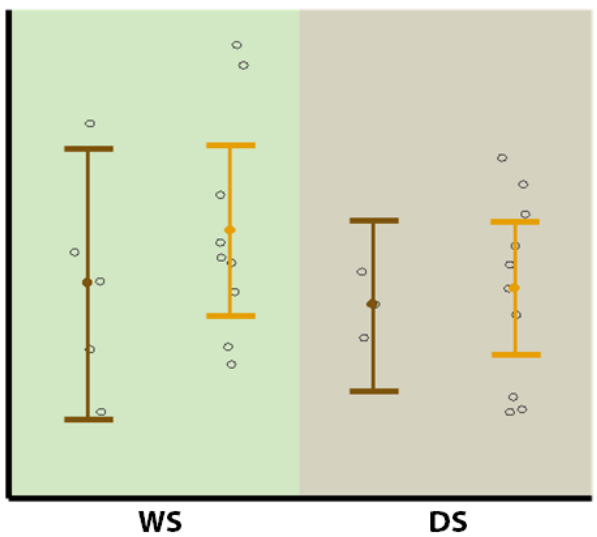

Decap

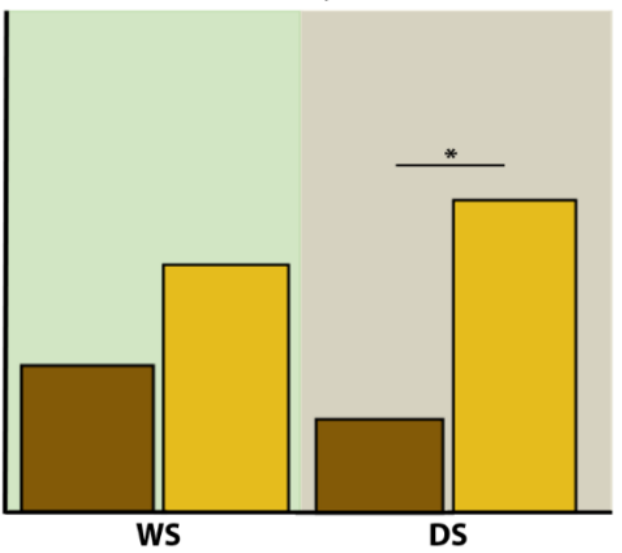


Fig S7. Generation of the Yellow-attP mutant knockout line. (A) Insertion of an attP sequence into exon 4 (annotated using LepBase ensemble), the attP insertion is shown in red, the major royal jelly domain is shown in green. (B) Gel images of the haemolymph PCR for identifying transgenic individuals. Gel a shows the PCR products using primers designed to the attP insert. Gel $b$ shows the PCR products using primers designed to the yellow coding sequence spanning the attP insertion which reveals which animals are heterozygous or homozygous based on the number and size of the PCR band. Individual no. 1 shows 2 bands thus has both the Wt and attP genome. Individual no. 2 shows only 1 band which is slightly larger meaning it has the attP genome only. Individual no. 5 shows only a single small band thus has the Wt genome only. (C) Alignment of the yellow sequence with the corresponding region from the yellow-attP line. (D) Phenotype of the Yellow mutant knockout butterflies (left) and Wt (right).
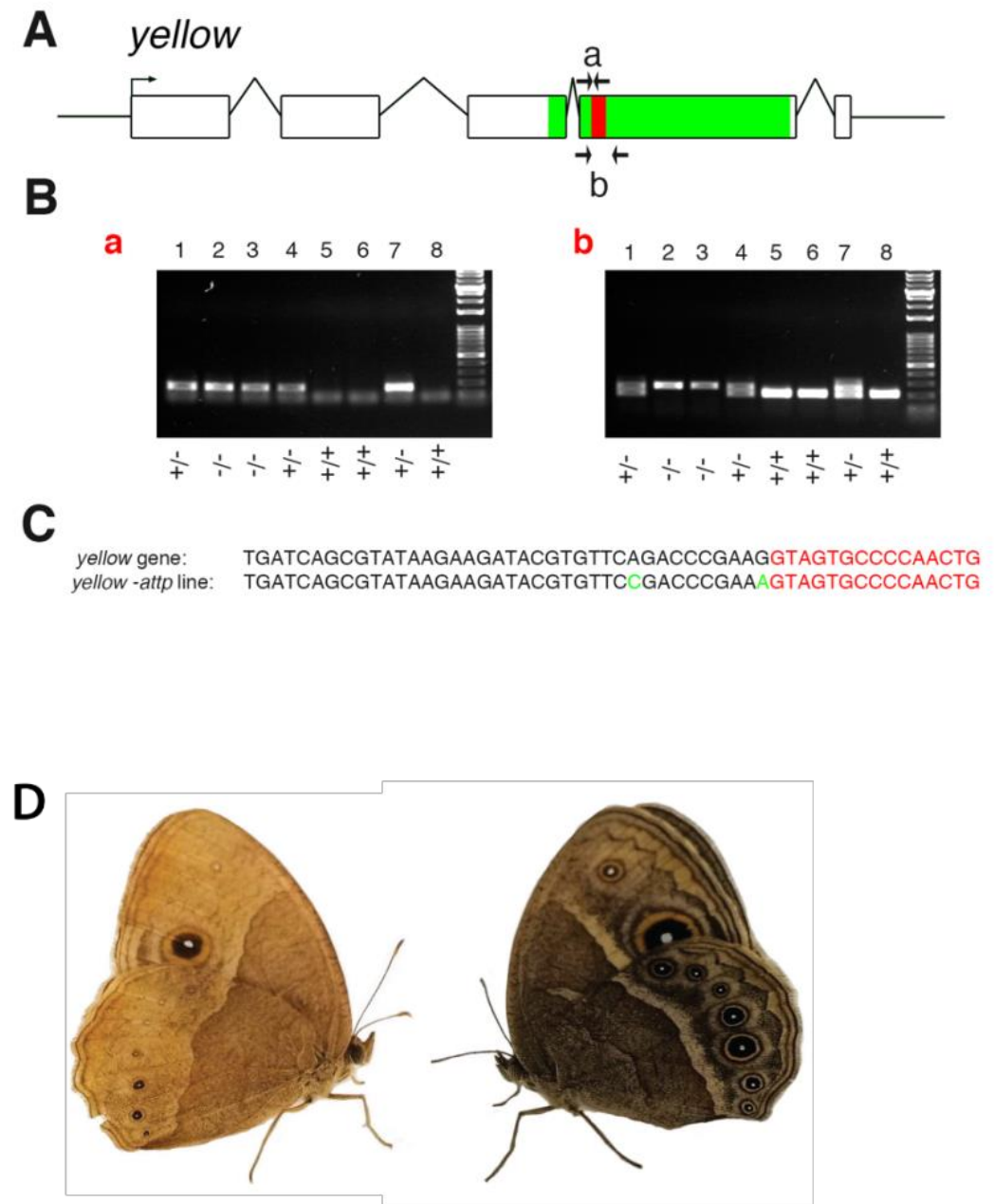